\title{
Research on seismic performance of traditional Chinese hall-style timber buildings in the Song and Yuan dynasties (960-1368 AD): a case study of the main hall of Baoguo Temple
}

\author{
Yijie Lin, Qing Chun *, Chengwen Zhang, Yidan Han and Hui Fu
}

\begin{abstract}
The hall-style timber frame built in the Song and Yuan dynasties (960-1368 AD) is one of the most important structural prototypes of the traditional timber architecture in East Asia. The current research, through a typical case of the main hall of Baoguo Temple in Ningbo, China, aims to present an accurate and effective seismic performance evaluation method applicable to hall-style timber structures without time-cost expenditure. To obtain more realistic seismic response of hall-style timber frame, a simplified numerical model of the main hall of Baoguo Temple is established based on in situ measurements and low-cycle reversed loading tests results of mortise-tenon joints, moreover, nonlinear static pushover analysis has been performed to quantify the seismic performance levels under five loading conditions. The generalized force-deformation relationship of the timber plastic hinges is modified regarding to the moment-rotation curves of four special mortise-tenon joints. The seismic behaviour of global hall-style timber frame is evaluated through capacity spectrum method and verified by time history analysis, local failure mechanisms are evaluated by the occurrence sequence of plastic hinges. Finally, a performance-based assessment method adequate for the traditional hall-style timber architectures has been proposed with comparison to the current codes. The results have shown that the structural stiffness of the width-direction is less than that of the depth direction due to the asymmetrical configuration of the timber frame, and the building can maintain a stable state under large lateral displacement before collapsing. The inter-storey drift angles of the building under peak ground accelerations of $0.1 \mathrm{~g}, 0.2 \mathrm{~g}$, and $0.3 \mathrm{~g}$ are less than the suggested ultimate values in the current local codes, however, the main hall represents to be more vulnerable to damage when suffer seismic action along the width-direction. This research can provide a reference for seismic performance evaluation and preventive conservation of ancient hall-style timber architectural heritage.
\end{abstract}

Keywords: Hall-style timber frame, Performance level, Mortise-tenon joints, Nonlinear static pushover analysis, Seismic assessment method

\section{Introduction}

In the development process of traditional architecture in East Asia, ancient timber building is the main composition implemented in the existing architectural heritage. The hall-style timber frame is originated in the

*Correspondence: cqnj1979@163.com

School of Architecture, Southeast University, Nanjing 210096, China late Tang dynasty (857-960 AD) and gradually standardized in the Song and Yuan dynasties (960-1368 AD). In fact, hall-style timber frame plays a significant role and makes positive effect on the technical achievements of timber structures in East Asia. For more than 1000 years, hall-style timber buildings remained in earthquake-prone region are proven to be highly vulnerable due to its uncertain seismic behaviour related 
to geometry shortcomings, material degradation and structural damage. Nevertheless, current seismic codes or regulations of ancient Chinese timber structures usually focus on qualitative conclusions of configuration requirements, lacking unified and accurate quantitative assessment index for seismic performance. Hence, a seismic performance evaluation method applicable for hall-style timber buildings is urgently needed.

The analysis of the internal tectonic system of hallstyle timber buildings in the Song and Yuan dynasties is the basis for establishing the analysis model due to complex joints and internal construction related to uncertain behaviours under earthquake. It should be noted that when subjected to seismic excitation, elastoplastic behaviours usually occur at mortise-tenon joints, while the deformation of the whole timber frame is relatively small [1]; thus, many experiments and numerical simulations have conducted on the mechanical properties of mortise-tenon joints. Chen et al. [2] conducted an experimental analysis on five types of joints of a historic building in Yangzhou. The results indicate that the bearing bracket in the tenon can improve the pulling-out resistance capacity, rotational stiffness, energy dissipation of mortise-tenon joints and reduce the bending capacity. Zhang et al. [3] applied the fast nonlinear analytical method to predict the global response of traditional Chinese timber buildings under seismic excitation, considering the mechanical behaviour of sliding column roots, mortise-tenon joints and Dou-Gong (bracket sets). Ma, Xue et al. [4, 5] analysed dovetail joints with different damaged cases and different degrees of damage and found that partially damaged mortise-tenon joints still present great seismic performance. Tanahashi et al. [6] have indicated that rotational resistance of traditional Japanese mortise-tenon joints have proven to play important roles in seismic performance of traditional timber buildings. Ogawa et al. [7, 8] carried out experimental and theoretical research of traditional Japanese Watariago joints and quantify the mechanical properties influence of the gap size of mortise-tenon. Chang et al. [9] and Fujita et al. [10] have conducted moment resisting tests of Nuki-column joints, which are commonly used in traditional timber structures of Japan and Taiwan, to investigate the mechanical models and complex behaviour of this kind of joint. To improve the elastic stiffness of Nuki joints, Hiroto et al. [11] have proposed that hardwood used for Nuki joints makes significant effect on structural performance through tests of three different type Nuki joints. The above research illustrates that mortise-tenon joints have a crucial effect on the seismic responses of the global structure, and the bearing capacity and failure modes of the joints are the most important basis for the overall timber frame performance evaluation.

From the perspective of the seismic performance of timber structures, many researchers have conducted shaking table experiments, in situ dynamic tests and finite element numerical simulations on the dynamic characteristics of traditional timber structures in East Asia. Xue et al. [12] established a simplified dynamic analysis model of the palace-style roof timber structure, focused on the influence of roof quality and the parallel elastic modulus on the structure's dynamic characteristics. Yeo et al. [13] conducted three quasi-static cyclic tests on the traditional Dieh-Dou timber frame under different working cases and proposed a theoretical model to evaluate the structural behaviour of the Dieh-Dou timber frame. Suzuki et al. [14] performed shaking table tests and static tests to clarify that traditional timber frame had large flexibility and deformability. Watanabe et al. [15] and Toyoda et al. [16] carried out vibration measurements of typical timber temples built in seventeenth century to inspect the frequencies accuracy of structural model consists of joint spring, column, beam and hanging wall. Recent studies indicate that traditional timber structures have high-efficiency earthquake resistance, but numerical simulations are still focused on verifying experimental phenomena, lacking discussion on the seismic performance level of historical timber buildings. Since the hall-style timber structures in the Song and Yuan dynasties are quite different from the existing research in terms of architectural patterns and mortisetenon joint connections, a more realistic and efficient analysis should be carried out on these priceless relics.

Summarizing the abovementioned research, in research on the seismic performance of traditional Chinese timber structures, limited research has been done to discuss the global structural performance of the hallstyle timber frame in the Song and Yuan dynasties, which takes an important part in built timber structures in East Asia. The purpose of this research is to propose a timesaving and effective method for seismic performance evaluation of hall-style timber buildings through a case study. By analysing the existing research and relics of the hall-style timber structure in the Song and Yuan dynasties, the main hall of Baoguo Temple is selected as a representative case in this paper. The proposed assessment method includes four steps. First, a simplified finite element model of the hall-style timber frame is established based on the in situ measurement of the main hall of Baoguo Temple and the experimental results of four typical mortise-tenon joints. Then, the seismic performance levels of the hall-style timber frame are determined by comparing the existing codes of many countries, and the performance levels of the plastic hinge of the component 
are identified according to the moment-rotation relationship of the mortise-tenon joints. After that, a nonlinear pushover analysis method is adopted to obtain the seismic response of the hall-style timber frame and the failure sequence of the components under five working conditions. The results are verified through time-history analysis. Finally, according to the above analysis, the inter-storey drift angles corresponding to the five performance levels of the hall-style timber frame are obtained. The research results provide a useful reference for rapid seismic performance assessment and repair measures and monitoring technique of valuable historical timber structures.

\section{Description of the hall-style timber frame} Major structural components of the hall-style timber frame From the aspect of the tectonic system of ancient timber frame structures, the hall-style timber structure developed in southern China in Song and Yuan dynasties (960-1368 AD) is regarded as a prototype of traditional timber buildings in East Asia [17, 18]. In the tenth to fourteenth century, extensive cultural exchanges in East Asian countries have enabled Chinese timber frame construction technology to be widely accepted and introduced in the middle age of Japan and in the Goryeo period of Korea, several Daibutsu-yo [19, 20], Zen-style [21] and Jusimpo-style [22] buildings have been established and evaluated based on the hall-style timber frame. In the fourteenth to twentieth century, hall-style timber frames were still commonly used in a variety of architectural typologies including palaces, dwellings, Chinese classic gardens, and temples.

The internal geometry features of hall-style timber frame are the foundation to understand the global structural behaviour. Based on the recordings in Yingzaofashi [23], an official Chinese construction regulation promulgated in the Song dynasty (1103 AD), the beam-column configuration of hall-style timber frame can be flexibly changed according to the requirements of architectural types and continuing application. For the hall-style timber frame, a single longitudinal frame is the basic unit constituted the whole structure, which can be classified into symmetrical configuration and asymmetrical configuration in accordance with the different distance of the first to second columns and the third to fourth columns in the same longitudinal frame, as shown in Fig. 1. Comparing the original planes of existing hall-style timber buildings in China and related relics in other countries built in the 10th-14th Century, asymmetrical configuration with four-column-nine-purlin pattern is more common than others. This phenomenon can be explained from the application of religious use that more front space can be obtained from reducing the distance between the latter two columns [24].

Based on a survey of extant hall-style timber buildings and historical data, several construction methods that are conducive to lateral resistance have been adopted in the configuration of hall-style timber frames can be concluded as follows:

(1) Different from the more researched palace-style timber frame [12, 25], obvious structural layers cannot be identified in the vertical direction of the hall-style timber frame. The height of the interior and exterior columns is not equal, and the loadbearing beams are directly inserted into the column by mortise-tenon joints instead of being supported indirectly by the Dou-gong set.

(2) The depth-width ratio of hall-style timber buildings is close to 1 for the use of square planes, and the height-width ratio usually ranges from 0.7 to 1 , so the overall stiffness distribution of the hall-style timber buildings is more reasonable [26].

(3) To reduce the negative influence of structural stability by the height difference between the exterior columns and the interior columns, horizontal reinforcing components such as Chuans, tie beams and architraves will be added to both width and depth direction (Fig. 2). It should be noted that the Fubigong configuration in Fig. 2 is a typical decoration type in timber buildings built in tenth to fourteenth century $\mathrm{AD}$, but its structural contribution have been proved inefficient $[27,28]$.

(4) The forms of the mortise-tenon joints of the hallstyle timber frame are complex and diverse, and the adoption of the mortise-tenon joints is carried out according to the force relationship of the connections and the importance of the components.

\section{A case study: the main hall of Baoguo Temple}

Recent studies on the geometry features and construction methods of ancient Chinese hall-style timber buildings built in the Song and Yuan dynasties have shown that of the main hall of Baoguo Temple, the construction approach, structural features and interior decoration can be recognized as the most similar case to the record of the hall-style timber frame in Yingzaofashi [29]. The main hall of Baoguo Temple in Ningbo ("the main hall" hereafter), Zhejiang Province is a Buddhist architecture built in 1013 AD (Fig. 3), proven to be the oldest existing timber building in the southern part of China and the earliest case of the application of asymmetrical configuration [24]. To obtain accurate geometrical data, in situ measurements were carried 


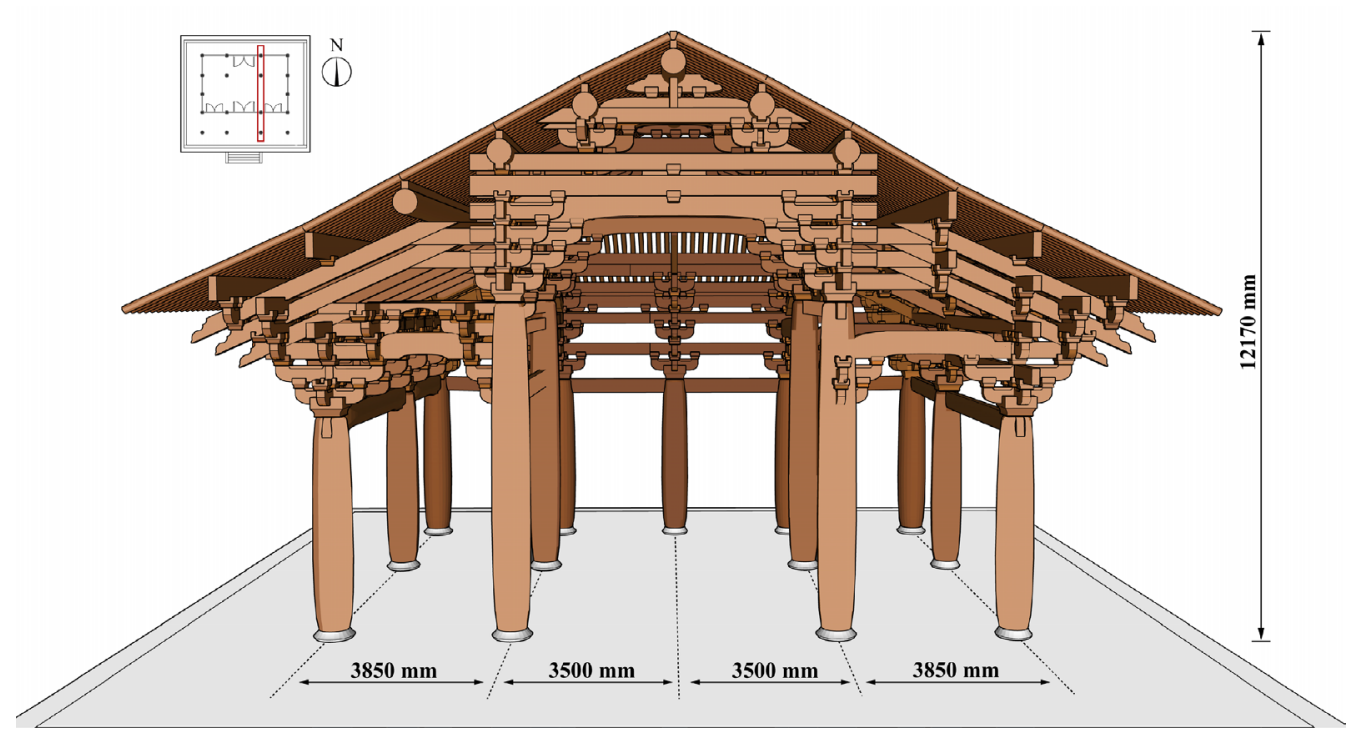

(a) A case of symmetrical configuration: the main hall of Hualin Temple

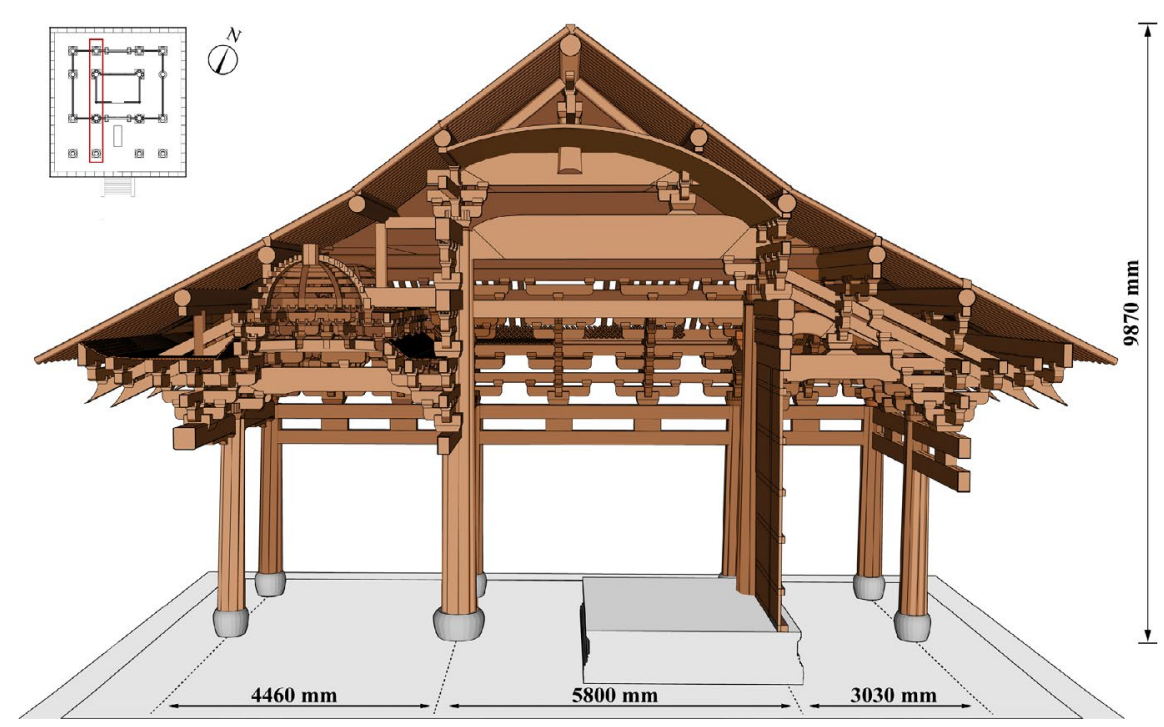

(b) A case of asymmetrical configuration: the main hall of Baoguo Temple

Fig. 1 The symmetrical and asymmetrical configurations of the hall-style timber frame

out by a Leica Scan Station P16 scanner (Leica, Wetzlar), as a three-dimensional scanning cloud image of the main hall shown in Fig. 4. The part of the structure built in the Song dynasty in this building is a square plane with a width of $11.83 \mathrm{~m}$ and a depth of $13.38 \mathrm{~m}$. The width-depth ratio is 0.88 , the height-width ratio of the building is 0.841 . Based on the observations in the in situ survey and historical documents [30], four different types of mortise-tenon joints are adopted in the main hall due to the special mechanical characteristics of the components in Fig. 5. Niekougumao mortise-tenon joints are used to link the reinforcement members such as the architraves, Chuan components and tie beams to the top of columns, while Tou mortise-tenon joints are adopted to connect tension members to the middle of the central columns. Straight mortise-tenon joints are selected to connect beams 


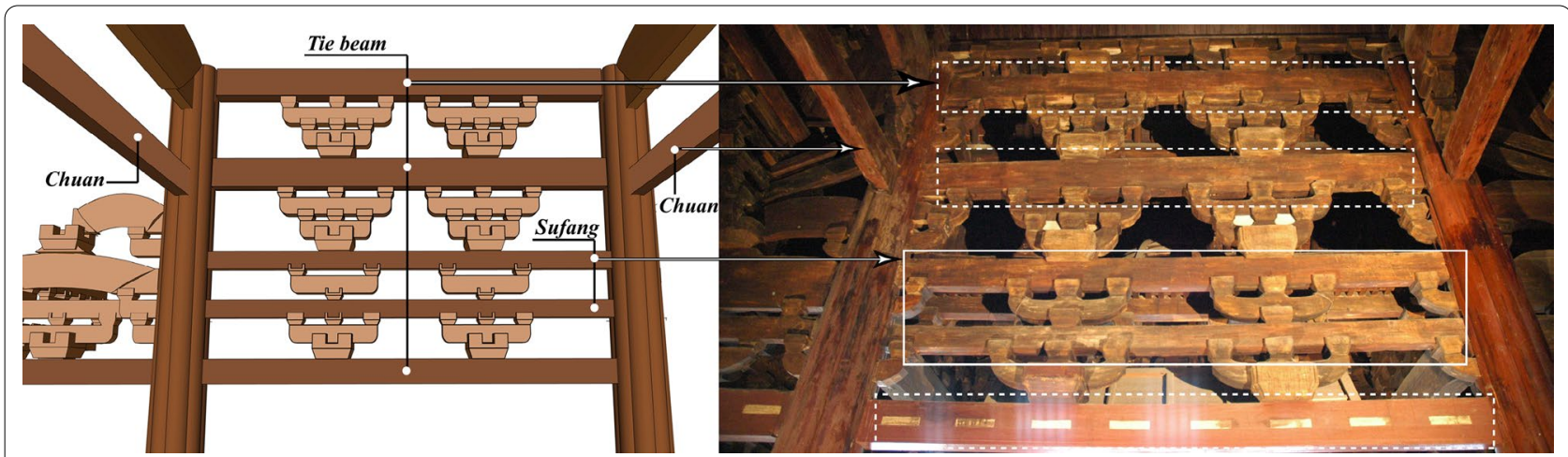

Fig. 2 Reinforcing timber components in the main hall of Baoguo Temple

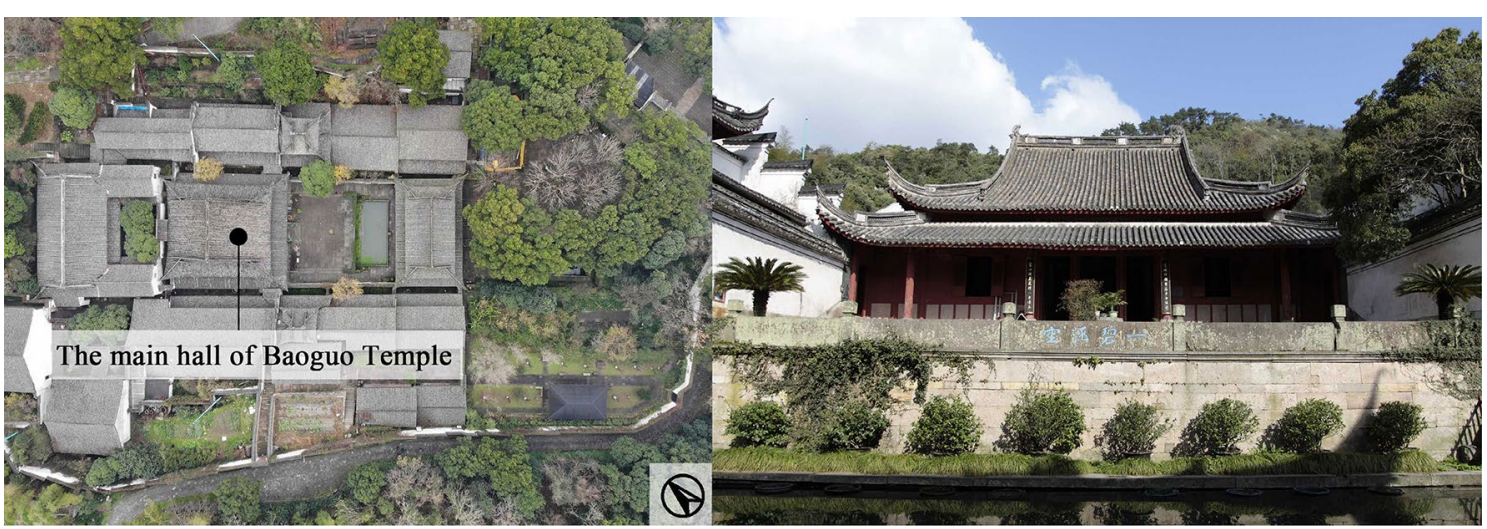

Fig. 3 The main hall of Baoguo Temple

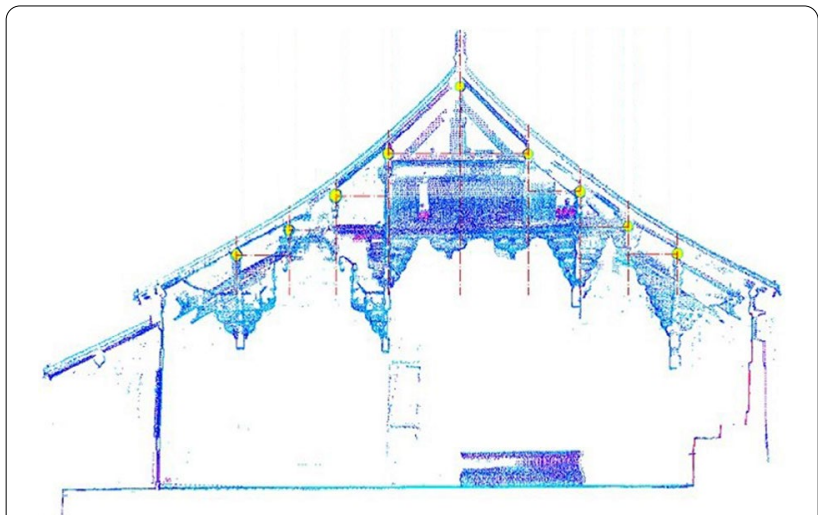

Fig. 4 The three-dimensional scanning cloud image of the main hall

and other compression members that intersect with columns, and the connection between the foot of the melon column and the two-purlin beam is a vertical straight mortise-tenon joint. Since the main hall represents a typical hall-style timber frame built in Song and
Yuan dynasties, it is selected as a representative case of this research.

\section{Experiment analysis of mortise-tenon joints Test setup}

To establish an accurate finite element model based on the structural performance of the four typical mortisetenon joints in the main hall, a low-cycle cyclic loading test was set up according to the previous research [31, 32] to obtain the mechanical properties of the mortisetenon joints. According to the configuration of mortise-tenon joints recorded in Yingzaofashi and the actual structure of the main hall, four specimens of different types of mortise-tenon joints, which were Niekougumao mortise-tenon joint(NMT joint) (Fig. 6a), Tou mortisetenon joint(TMT joint) (Fig. 6b), Straight mortise-tenon joint(SMT joint) (Fig. 6c), and Straight mortise-tenon at the foot of melon column(SMTM) (Fig. 6d), were prepared based on the scale ratio of 1:1.76. The geometric proportion relationship between the specimens and the original components is shown in Table 1. 


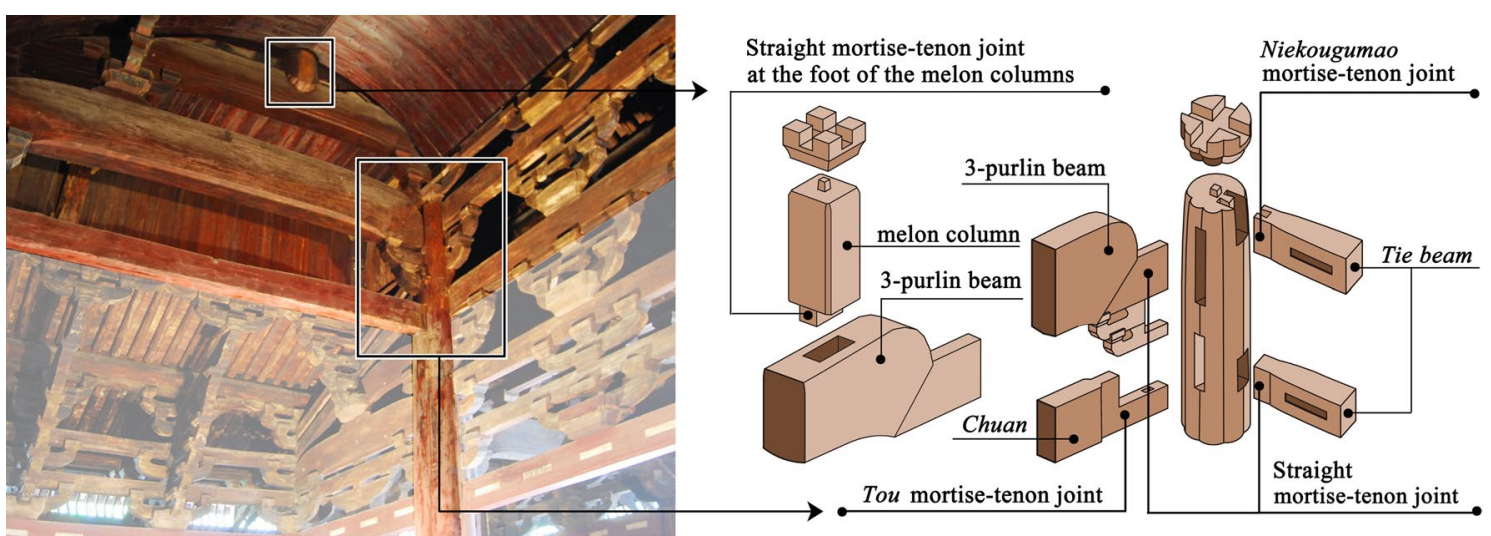

Fig. 5 Four different types of mortise-tenon joints in the main hall

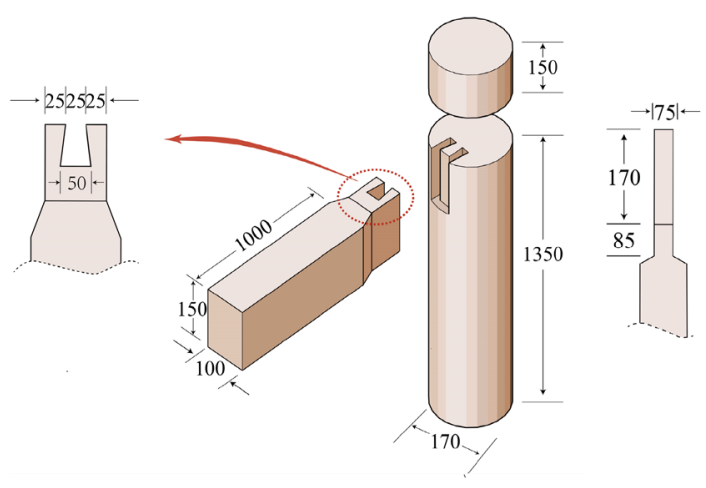

(a) Niekougumao mortise-tenon joint (NMT joint)

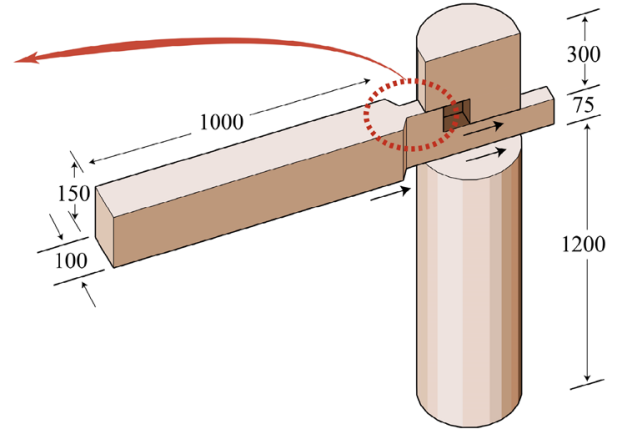

(b) Tou mortise-tenon joint (TMT joint)

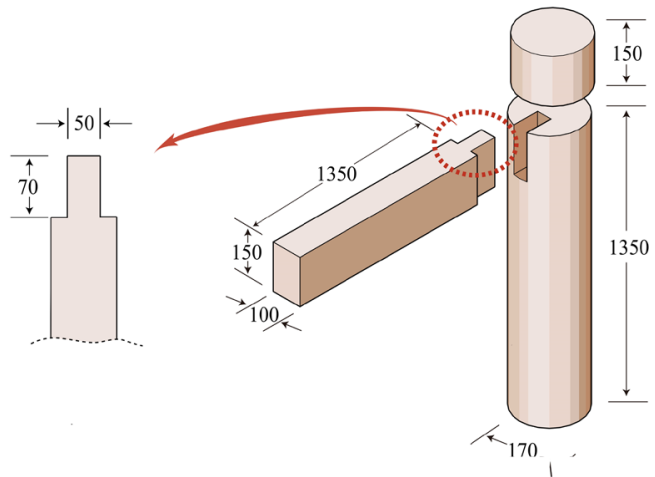

(c) Straight mortise -tenon joint (SMT joint)

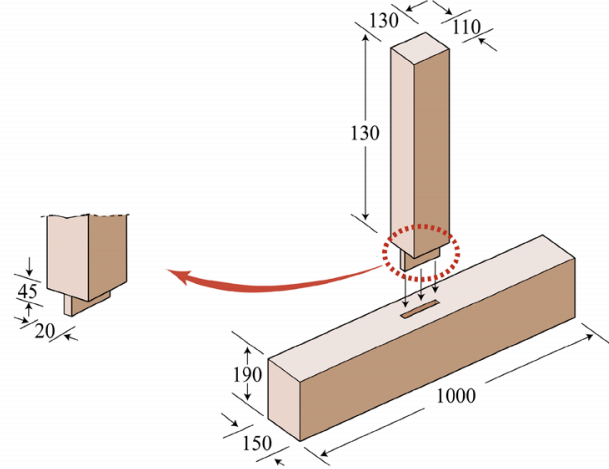

(d) Straight mortise-tenon joint at the foot of melon column (SMTM)

Fig. 6 Four different mortise-tenon joints specimens (unit: $\mathrm{mm}$ )

According to the tree species identification record of the main structural components [30], the main hall are mainly made of Chinese fir (Cunninghamia lanceolata (Lamb.) Hook.), which has been the major plant species in southern China for hundred years, for its fast-growing characteristics and great mechanical properties [33]. The tests were carried out at Civil Engineering Laboratory of Nanjing University of Aeronautics \& Astronautics. The 
Table 1 Proportion relationship between the specimen and the original components

\begin{tabular}{llllllllll}
\hline Parameter value & Length & $\begin{array}{l}\text { Elastic } \\
\text { modulus }\end{array}$ & Displacement & $\begin{array}{l}\text { Angular } \\
\text { displacement }\end{array}$ & Stress & Strain & Mass & Moment & Shear force \\
\hline Relational expression & $S_{L}=L_{m} / L_{P}$ & $S_{E}$ & $S_{X}=S_{L}$ & $S_{\theta}$ & $S_{\sigma}$ & $S_{\varepsilon}=S_{\sigma} / S_{E}$ & $S_{m}=S_{\sigma} S_{L}{ }^{2}$ & $S_{M}=S_{\sigma} S_{L}{ }^{3}$ & $S_{F}=S_{\sigma} S S_{L}{ }^{2}$ \\
Model/structure & $1: 1.76$ & 1 & $1: 1.76$ & 1 & 1 & 1 & $(1: 1.76)^{2}$ & $(1: 1.76)^{3}$ & $(1: 1.76)^{2}$ \\
\hline
\end{tabular}

Table 2 Parameters of material properties of Chinese fir

\begin{tabular}{lllll}
\hline $\begin{array}{l}\text { Elasticity } \\
\text { modulus / } \\
\text { MPa }\end{array}$ & $\begin{array}{l}\text { Tensile } \\
\text { strength } \\
\text { parallel to } \\
\text { grain /MPa }\end{array}$ & $\begin{array}{l}\text { Compressive } \\
\text { strength } \\
\text { parallel to } \\
\text { grain /MPa }\end{array}$ & $\begin{array}{l}\text { Shear } \\
\text { strength } \\
\text { parallel to } \\
\text { grain } / \mathrm{MPa}\end{array}$ & $\begin{array}{l}\text { Bending } \\
\text { strength } \\
\text { /MPa }\end{array}$ \\
\hline $10,238.1$ & 91.40 & 30.00 & 3.60 & 50.00 \\
\hline
\end{tabular}

material used for specimens was the same batch of airdried Chinese fir, the moisture content of wood was $12 \%$. During the test, the temperature and relative humidity of the environmental condition were controlled in the range of $22-28{ }^{\circ} \mathrm{C}$ and $47-60 \%$, respectively. The material properties tests were carried out according to the requirements of relevant Chinese standards [34-37], material tests samples were all taken from the same batch of Chinese fir of test specimens, the results of the mechanical parameters of specimens are shown in Table 2. The loading device of this test is shown in Fig. 7. A low-cycle repeated loading method was adopted in this test, and the vertical loading of $10 \mathrm{kN}$ was kept constant on the top of the column by the hydraulic jack. The displacement control method was used for vertical loading. The first loading cycle displacement was $10 \mathrm{~mm}$, and every additional $10 \mathrm{~mm}$ was the load-displacement of the next cycle.

\section{Test results}

The tests were completed when the specimens were destroyed, or tenons were pulled out from mortises. When the four mortise-tenon joint specimens began to deform, noise due to material compression and squeezing was frequently heard. As the displacement loading increased, tenons began to pull out from mortises, squeezing deformation and local cracks began to occur on the surface of tenons. All four types of mortise-tenon joints pass through the elastic, yield, and failure stages when subjected to low-cycle cyclic loading. In the elastic stage, the rotation rigidity of these four groups of mortise-tenon joints remains unchanged. With increasing rotation angle, the joints are in the yield stage, the hysteresis curves have noticeable pinch effects, the slip value of the tenons increases with increasing rotation angle, residual deformation begins to appear, and the rotation rigidity of the joints continues to degenerate. As the rotation angle is increased continually, the bearing capacity of the joint begins to decrease, and the deformation continues to increase until they finally fail. The failure mode of the four types of mortise-tenon joints was that tenons were pulled out from mortises (Fig. 8). From the load-displacement curves shown in Fig. 9, the hysteretic curves of the NMT joint, TMT joint and SMT joint appear to have a "Z" shape, and the hysteretic curve of the SMTM joint

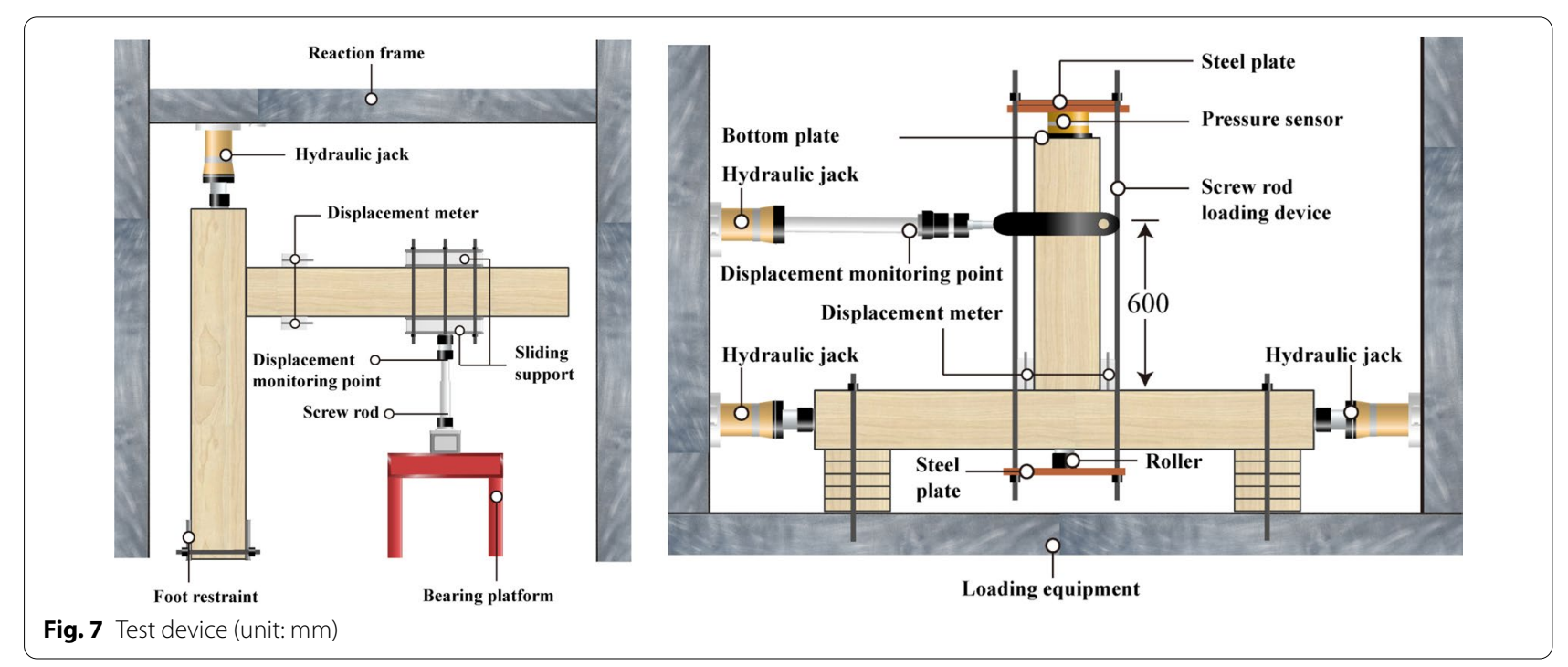




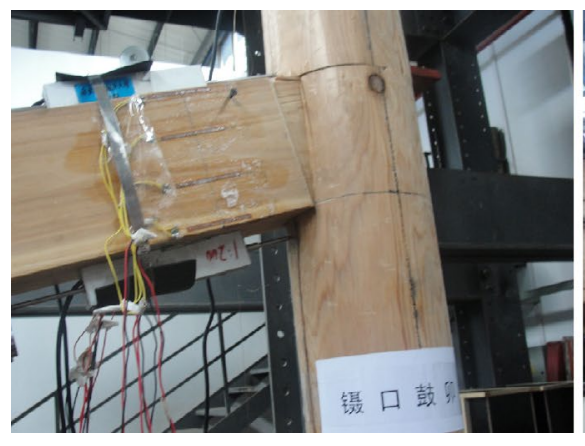

(a) Destruction of the NMT joint.

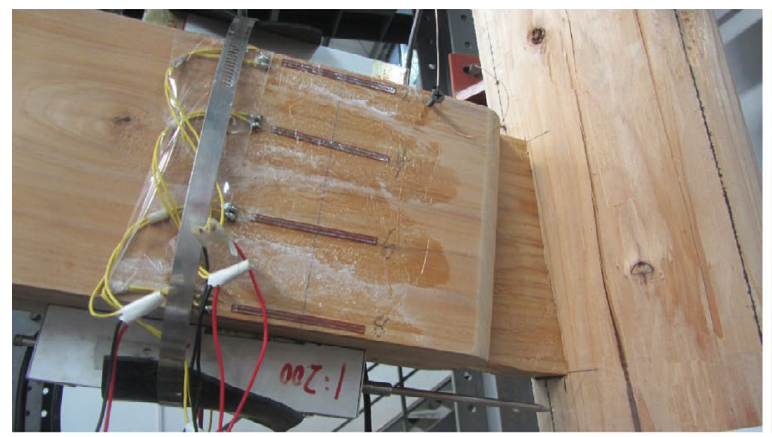

(c) Destruction of the SMT joint

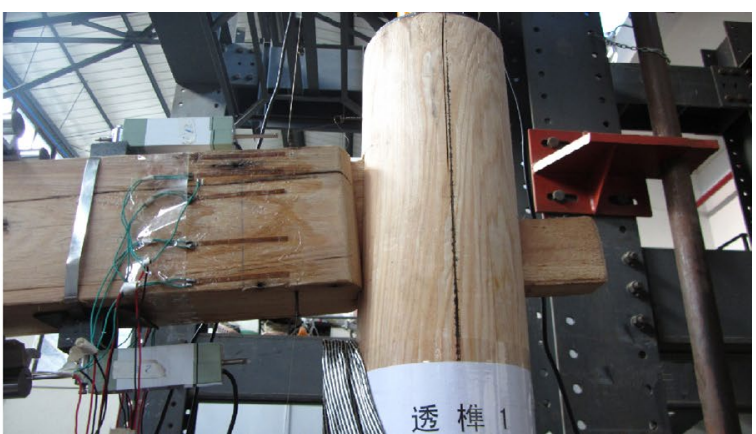

(b) Destruction of the TMT joint.

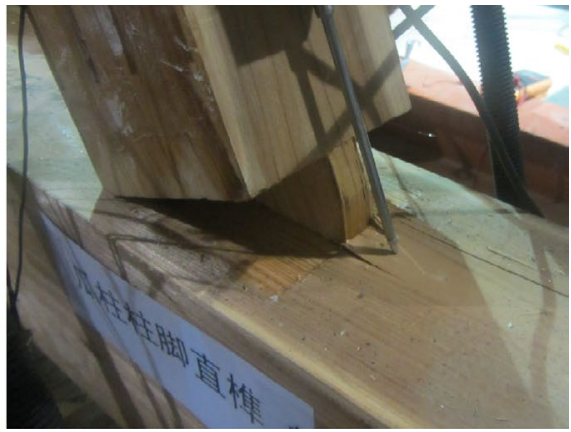

(d) Destruction of the SMTM

Fig. 8 Failure modes of four different mortise-tenon joint specimens

appears to have a reverse "S" shape. Based on the analysis of test data, the skeleton curves of these four types of mortise-tenon joints can be simplified as the trilinear model shown in Fig. 10, the semi-rigid calculation models can be written as Eq. (1), and the eigenvalues of this model are shown in Table 3:

$$
M= \begin{cases}K_{1} \theta & \theta \leq \theta_{1} \\ K_{1} \theta_{1}+K_{2}\left(\theta-\theta_{1}\right) & \theta_{1} \leq \theta \leq \theta_{2} \\ K_{1} \theta_{1}+K_{2}\left(\theta_{2}-\theta_{1}\right)+K_{3}\left(\theta-\theta_{2}\right) & \theta_{2}<\theta \leq \theta_{3}\end{cases}
$$

In Eq. (1), the values of $K_{1}, K_{2}, K_{3}, \theta_{1}, \theta_{2}$ and $\theta_{3}$ of the four types of mortise-tenon joints in different stages are obtained from Table 3.

From the results shown in Table 3, the elastic rotational rigidity of different mortise-tenon joints indicated a large difference in mechanical characteristics, which may lead to different failure modes under seismic exactions.

\section{Performance-based seismic assessment}

The performance-based seismic evaluation method, which can help engineers formulate rapid risk assessment and efficient remedial measures, has been widely applied in multiple national regulations [38, 39]. The performance levels of the whole structure are evaluated by comparing the seismic demands of the whole structure with the seismic responses of each component to identify the maximum seismic safety that an existing building can perform under various hazard levels, and the performance levels of each component are divided by the change trend of material performance in the process of loading. According to the relevant evaluation criteria of seismic performance levels of components and global structure suggested by ATC-40 [38], FEMA-356 [39], FEMA-273 [40] and ASCE41 [41], and shaking table test results of timber structure with same architectural features $[1,42]$, the definition of performance levels in this research is described as:

Operational (OP): the global timber frame is basically intact. The mortise-tenon joints are still in the elastic deformation stage, and the principal load-bearing components are not damaged.

Immediate occupancy (IO): the timber frame is slightly damaged. Few mortise-tenon joints are in the yielding stage, but no tenon has pulled out of the mortise. The structure still retains its most original stiffness and strength.

Life safety (LS): the timber frame is moderately damaged. Few tenons pulled out of the mortise and were 


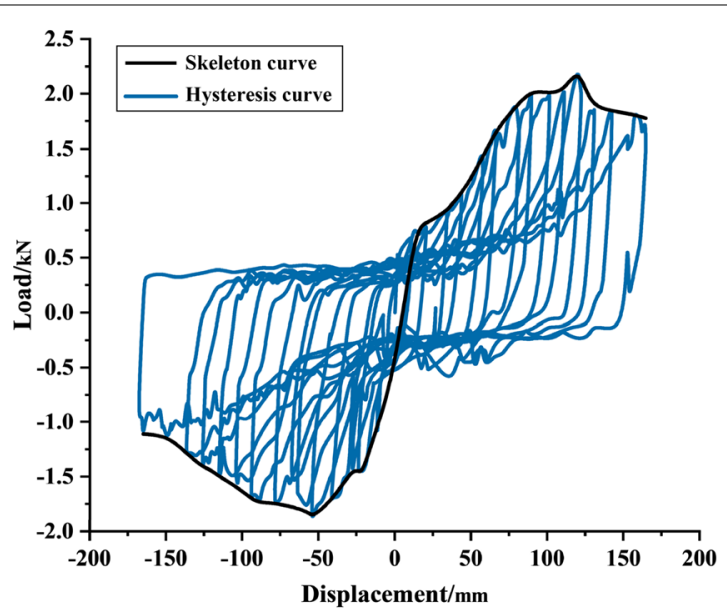

(a) Load-displacement curve of NMT joint

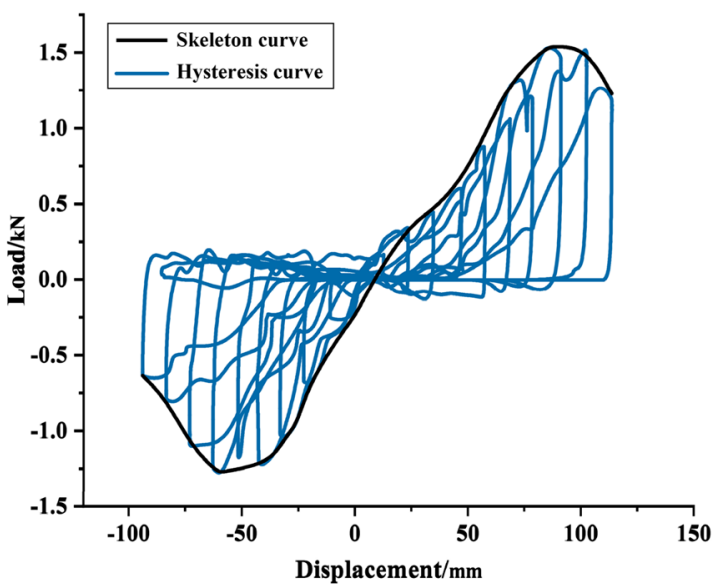

(c)Load-displacement curve of SMT joint

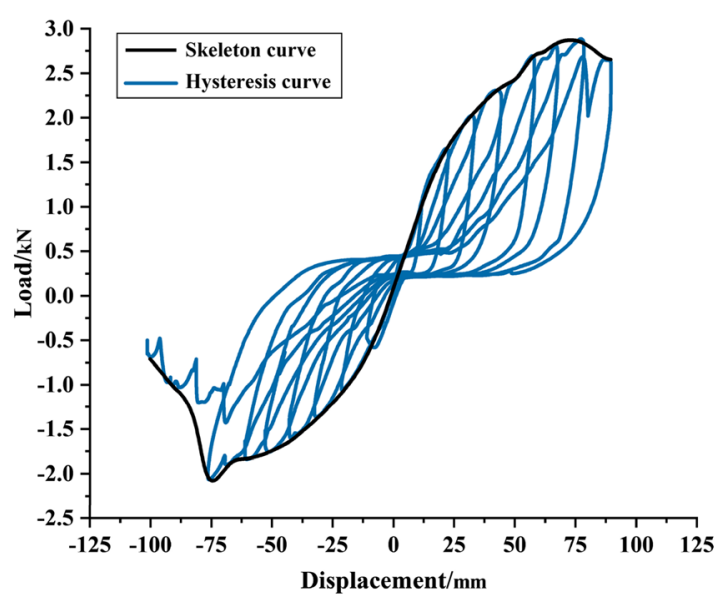

(b) Load-displacement curve of TMT joint

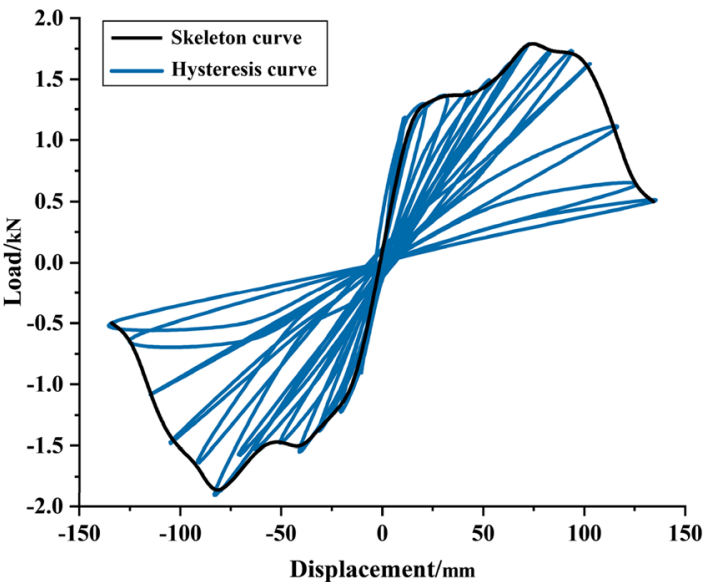

(d)Load-displacement curve of SMTM joint

Fig. 9 Load-displacement curves and skeleton curves of four different mortise-tenon joints

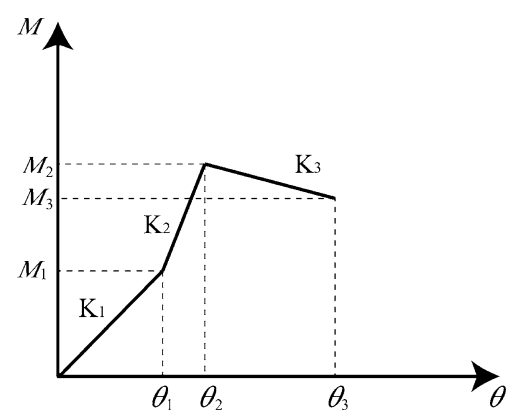

Fig. 10 Simplified trilinear model of $M-\theta$ skeleton curves of the mortise-tenon joints accompanied by slight cracks. The global structure may have lost a significant amount of its stiffness, but a large margin remains for additional lateral deformation before collapse can occur.

Collapse prevention (CP): the timber frame is severely damaged. Many tenons have pulled out of mortises. If the lateral deformation exceeds this performance level, the columns are skewed, and the structure may become unstable or collapse.

Collapse $(\mathrm{C})$ : the timber frame is severely deformed or even collapses. 
Table 3 Eigenvalues of the simplified trilinear model of the mortise-tenon joints

\begin{tabular}{|c|c|c|c|c|c|c|c|c|c|}
\hline \multirow{2}{*}{$\begin{array}{l}\text { Types of mortise- } \\
\text { tenon joints }\end{array}$} & \multicolumn{2}{|c|}{ Elastic stage } & \multicolumn{2}{|c|}{ Yield stage } & \multicolumn{2}{|c|}{ Failure stage } & \multicolumn{3}{|c|}{ Characteristic stiffness } \\
\hline & $\begin{array}{l}M_{1} / \\
\mathrm{kN} \cdot \mathrm{m}\end{array}$ & $\theta_{\mathrm{y}} / \mathrm{rad}$ & $\begin{array}{l}M_{2} / \\
\mathrm{kN} \cdot \mathrm{m}\end{array}$ & $\theta_{\mathrm{u}} / \mathrm{rad}$ & $\begin{array}{l}M_{3} / \\
\mathrm{kN} \cdot \mathrm{m}\end{array}$ & $\theta_{0} / \mathrm{rad}$ & $\mathrm{K} 1$ & K2 & K3 \\
\hline NMT joint & 2.13 & 0.02 & 6.08 & 0.17 & 4.67 & 0.23 & 125.39 & 25.78 & -22.77 \\
\hline TMT joint & 6.16 & 0.04 & 8.55 & 0.08 & 7.94 & 0.11 & 146.68 & 58.24 & -20.35 \\
\hline SMT joint & 3.34 & 0.06 & 3.48 & 0.09 & 1.79 & 0.15 & 53.82 & 4.43 & -31.30 \\
\hline SMTM joint & 2.37 & 0.02 & 3.60 & 0.19 & 2.15 & 0.23 & 139.45 & 7.13 & -35.37 \\
\hline
\end{tabular}

The definition of the performance levels of the overall timber frame is determined by the seismic performance levels of each component. In the following, the connection properties of the mortise-tenon joints and the stress performance of the components are presented.

\section{Nonlinear static pushover method for the hall-style frame}

Due to the critical effects on conducting rapid seismic performance assessments in preventive preservation of architectural heritage, at present, the nonlinear static pushover (NSP) method, which can efficiently avoid thousands of iterations in a nonlinear inelastic time history analysis [43], has been applied to the seismic analysis of many historical relics with masonry structures in the past 10 years $[44,45]$. For the NSP method, incremental lateral loads along the height of the structure are applied in different ways to the structure until the structure reaches a predetermined target displacement or overturn. It mainly includes the capacity spectrum method [46] and N2 method [47], and a variety of derived loading methods have been used in different seismic designs [48, 49]. Compared with the N2 method, the capacity spectrum method (CSM) has a wider range of applications, while the N2 method is aimed at reinforced concrete buildings. However, neither method has been fully explored in the case of timber structures. Considering the extensive applicability and calculation simplicity of the structural performance evaluation method in the future practice of heritage protection engineering, SAP2000 V.22 finite element software (CSI, Berkeley) is used in the present research for pushover analysis [50].

\section{Description and validation of the finite element numerical model}

The finite element numerical model of the main hall was established as a spatially framed system based on the in situ measurement data from the three-dimensional scanner (Fig. 11). Beams, columns, purlins, and other components of the building were simplified to line elements. The material properties of the wood were set to orthotropic. Considering that ancient timber buildings have experienced long-term load condition and the material performance have a certain degradation [51], Chinese timber codes have regulated that when calculating the component strength of ancient timber buildings, the related material parameters are necessary to multiply a certain reduction factor. Since the building has a 1000-year history, the elastic modulus value considers the reduction coefficients of 0.75 recommended by relevant codes [52, 53]. The rest of the material property parameters are determined according to previous research [54] as shown in Table 4 and the structural damping ratio was assumed to be 0.05 . Considering that only friction would be applied to the connection of the column foot and the base stone, the boundary condition of the column bottom was set as a hinge. For the semi-rigid mechanical characteristics of the connections of ancient timber buildings, connections between the horizontal load-bearing members and the head of the columns were all assumed to be hinge joints. The rotational stiffness of the mortise-tenon joints was set based on the experimental results in Table 3. For the simulation of the Dou-gong, a beam-element model was adopted to simplify the inclined struts and trusses, and the bending moment at both ends of the inclined members was released as a hinge connection with other components. The connection of the columns and ground is simulated by a hinge. The infilled wall was not considered in the simulation because the original wall was made up of $6 \mathrm{~cm}$ bamboo woven bone plastered with mud [30], which barely contributes to the overall lateral stiffness. The dead load on the roof is $3.5 \mathrm{kN} / \mathrm{m}^{2}$, and the live load is $0.7 \mathrm{kN} / \mathrm{m}^{2}$ [26]. For the use of lumped mass matrix in this numerical simulation, the mass of the structure is equally distributed to each node, the coefficient of dead load is 1.0, the coefficient of live load is 0.5 [55]. In this study, the southwest corner column, which is denoted by SW in Fig. 11d, was taken as the origin of the coordinate, 


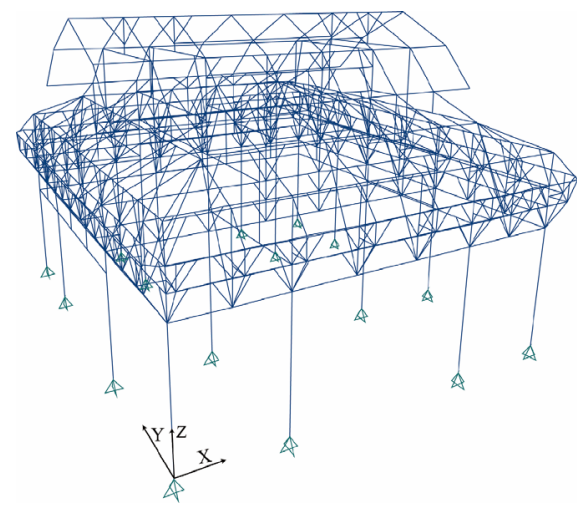

(a) The spactial element system
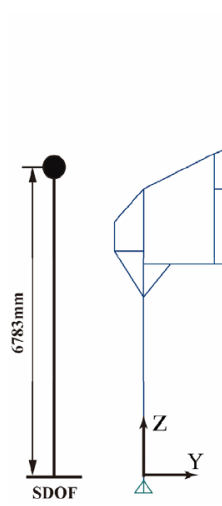

(c) The longitudinal section

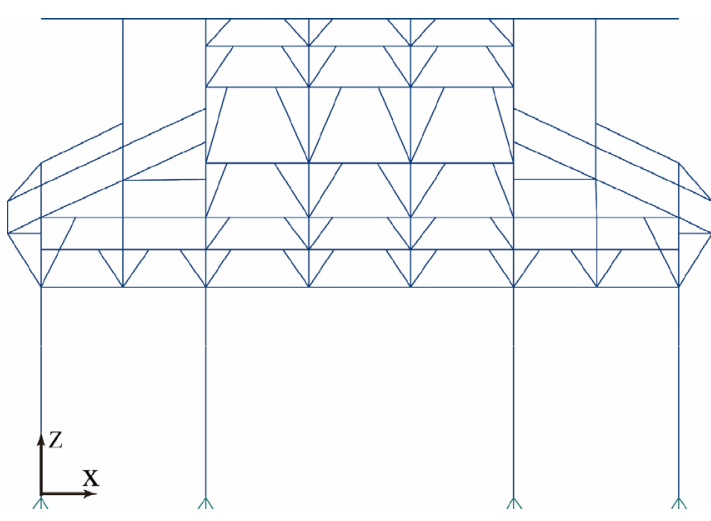

(b) The transiversal section

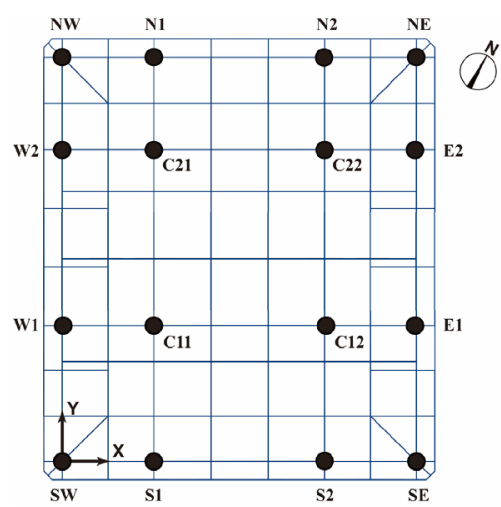

(d)The Top view and column number

Fig. 11 The finite element model of the main hall

Table 4 Elastic constants of Chinese fir

\begin{tabular}{llllllllll}
\hline $\begin{array}{l}E_{\mathrm{L}} \\
/ \mathrm{MPa}\end{array}$ & $\begin{array}{l}E_{\mathrm{T}} \\
/ \mathrm{MPa}\end{array}$ & $\begin{array}{l}E_{\mathrm{R}} \\
/ \mathrm{MPa}\end{array}$ & $\begin{array}{l}G_{\mathrm{L}, \mathrm{R}} \\
/ \mathrm{MPa}\end{array}$ & $\begin{array}{l}G_{\mathrm{L}, \mathrm{T}} \\
/ \mathrm{MPa}\end{array}$ & $\begin{array}{l}G_{\mathrm{R}, \mathrm{T}} \\
/ \mathrm{MPa}\end{array}$ & $\mu_{\mathrm{L}, \mathrm{R}}$ & $\mu_{\mathrm{L}, \mathrm{T}}$ & $\mu_{\mathrm{R}, \mathrm{T}}$ & $\begin{array}{l}f_{\mathrm{t}, \mathrm{L}} \\
/ \mathrm{MPa}\end{array}$ \\
\hline 6750 & 675 & 675 & 3110 & 311.50 & 311.50 & 0.30 & 0.30 & 0.30 & 64.22 \\
\hline
\end{tabular}

Reduction coefficients of elasticity modulus is $0.75[52,53] E_{\mathrm{L}} E_{T}, E_{\mathrm{R}}$ are longitudinal, tangential, and radial timber elasticity modulus, respectively; $G_{L, R}, G_{\mathrm{L}, \mathrm{T}}, G_{\mathrm{R}, T}$ are shear modulus in transverse section, radial section, and tangential section, respectively; $\mu_{\mathrm{L}, \mathrm{R}}, \mu_{\mathrm{L}, \mathrm{T}}, \mu_{\mathrm{R}, \mathrm{T}}$ are Poisson's ratios in transverse section, radial section, and tangential section, respectively; $f_{t, L}$ is tensile strength parallel to the grain; $f_{C, L}$ is compressive strength parallel to the grain

and the $\mathrm{X}$ and $\mathrm{Y}$ directions are defined as the width and depth directions, respectively.

\section{Static analysis}

According to static analysis, the maximum vertical displacement of $10.89 \mathrm{~mm}$ is at the middle part of Purlin C in the south side of the main hall (Fig. 12a). Since the main hall of Baoguo temple has the highest level of construction technology at that time, the roof is in the form of Xieshan-style. The complex construction of the Xieshanstyle roof leads to a relatively large roof load. However, the cross-sections of the purlins are generally small, the diameter of the ridged purlin is $362 \mathrm{~mm}$, and the diameter of other purlins is $312 \mathrm{~mm}$, leading to greater deformation of the purlins. In the middle part of the Purlin A and Purlin $\mathrm{C}$ of the north side, there also have greater deformation of $8.2-8.5 \mathrm{~mm}$ (Fig. 12b). Moreover, the purlins with no support at the ends directly overhang the eaves, resulting in a large deformation at both ends of Purlin A and Purlin B, with maximum displacement of $8.3 \mathrm{~mm}$. 
The deformation of single-eave-architrave between columns S1 and S2, as shown in Fig. 11a, also has greater displacement of $10.32 \mathrm{~mm}$, while the deformation of the double-eave-architraves between columns $\mathrm{N} 1$ and N2 in the north side of the building is relatively small with $3.32 \mathrm{~mm}$ displacement. The reason is that the doubleeave-architrave configuration between the eave-column in the gable sides and the north side plays an important role in reinforcing the tensile performance and share the overhanging roof load with eave purlins, the deformation in other three sides of the building is relatively unapparent.

\section{Modal analysis}

To obtain the structure's natural frequencies and mode shapes, modal analysis was performed to evaluate the participating mass value of each vibrating mode, as reported in Table 5. The natural frequency of the main hall is $0.47-10.95 \mathrm{HZ}$. In the third mode, the structural mass participation coefficients in the three directions of

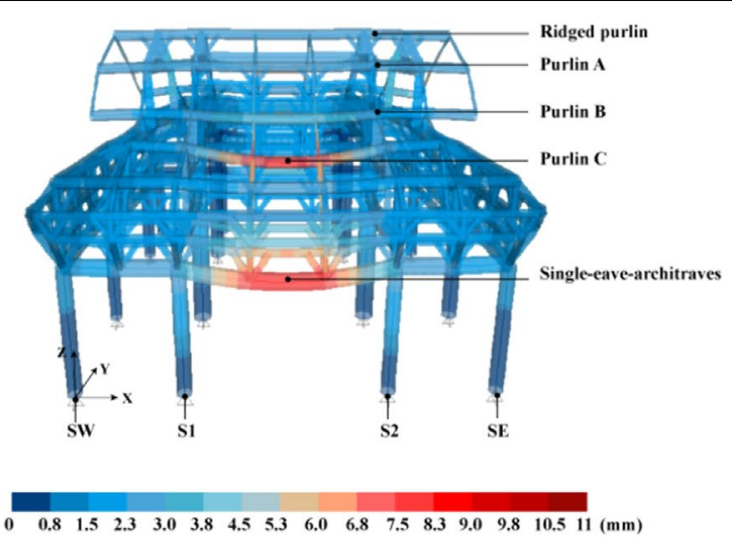

(a) Deformation of the south side

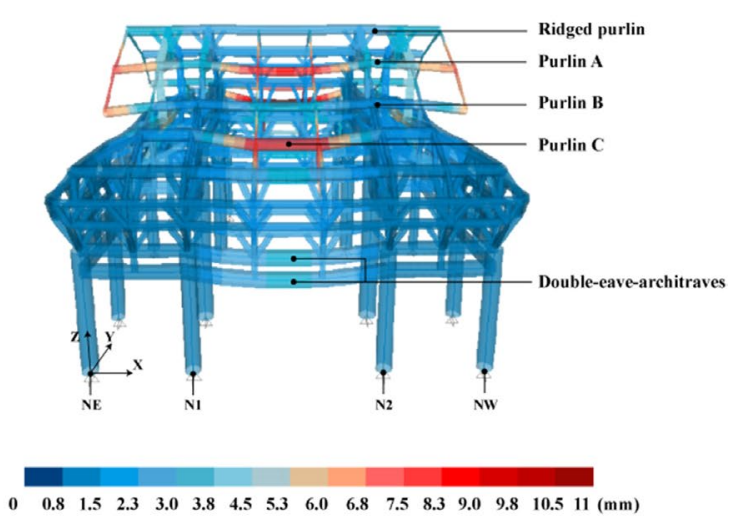

(b) Deformation of the north side

Fig. 12 Vertical deformation

Table 5 Modal analysis results

\begin{tabular}{lllllllllllll}
\hline Mode & $\begin{array}{l}\text { Period } \\
(\mathbf{s})\end{array}$ & Frequency (Hz) & UX\% & UY\% & UZ\% & SumUX\% & SumUY\% & SumUZ\% & RX\% & RY\% & RZ\% & Description \\
\hline 1 & 2.13 & 0.47 & 64.00 & 0.02 & 0.00 & 64.00 & 0.02 & 0.00 & 0.00 & 0.09 & 35.00 & $\begin{array}{l}\text { X-translation with } \\
\text { slightly Z-rotation }\end{array}$ \\
2 & 1.48 & 0.68 & 0.02 & 99.00 & 0.00 & 64.00 & 99.00 & 0.00 & 0.09 & 0.00 & 0.09 & Y-translation \\
3 & 1.03 & 0.97 & 35.00 & 0.00 & 0.00 & 99.00 & 99.00 & 0.00 & 0.00 & 0.02 & 98.00 & Global Z-rotation \\
\hline
\end{tabular}

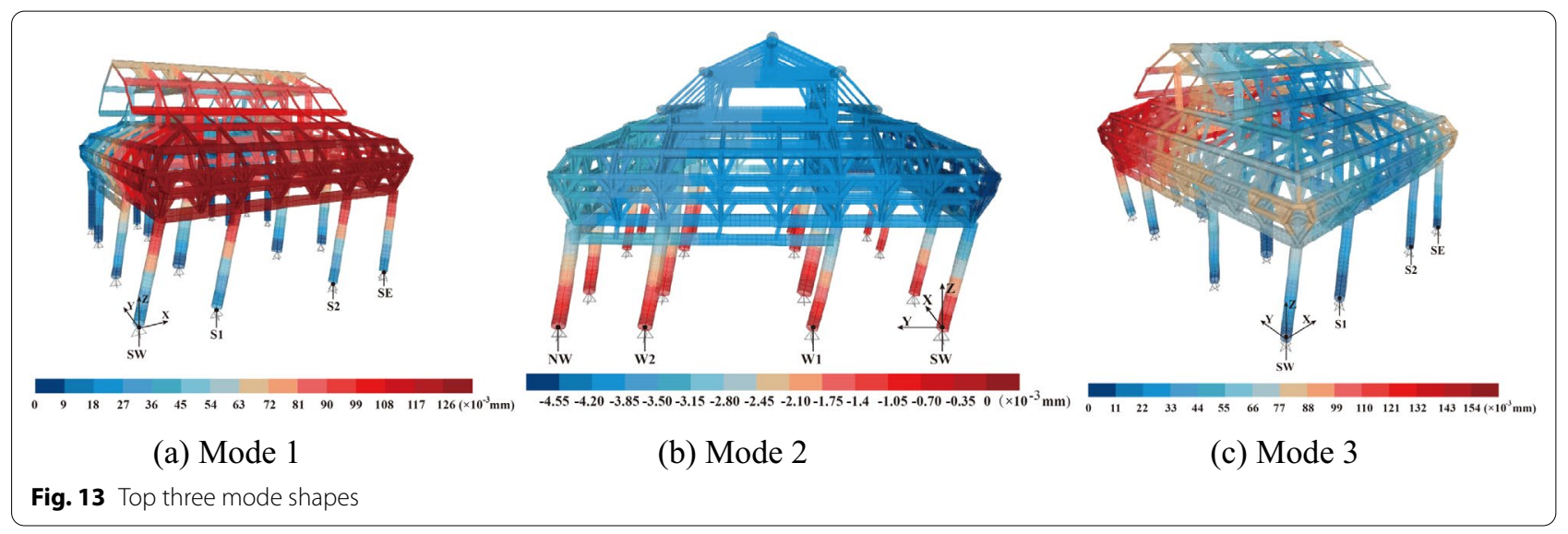


UX, UY, and RZ all reach 99\%. From the main three mode shapes shown in Fig. 13, it can be observed that the shape of mode 1 is horizontal vibration along the $\mathrm{X}$-direction with slight torsional vibration in the vertical direction (Fig. 13a), and mode 2 is horizontal vibration along the Y-direction (Fig. 13b), indicating that the stiffness in the width-direction of the main hall is less than the stiffness in the depth direction. The reason is that the asymmetrical configuration in the depth direction leads to stiffness asymmetry of the global building; moreover, the singleeave-architrave configuration between the eave-column SW to eave-column SE makes the horizontal connection weaker than that on the other sides, causing the structure to be easily affected by torsional vibration.

\section{Nonlinear static pushover analysis Plastic hinge model}

In SAP2000, the elastoplastic deformation of the component is simulated by the concentrated plastic hinge model, of which the hinge properties are defined as rigidplastic, and the deformation properties and inserted position of the plastic hinge need to be defined by the user. The default plastic hinge model presents the force-displacement relationship shown in Fig. 14a, where A is the origin, point $B$ represents the yield limit, $C$ represents the ultimate bearing capacity of the pushover analysis, point $\mathrm{D}$ is the residual strength of the pushover analysis, and point $\mathrm{E}$ represents complete failure. In section $\mathrm{BC}$, the four performance points of OP (operational), IO (immediate occupancy), LS (life safety), and CP (collapse prevention) represent the seismic performance thresholds of the building. The moment-rotation relationship obtained by former experimental results can be directly employed to define the nonlinear zero-length plastic hinges in timber structures, as shown in Fig. 14b [56].
Based on the experimental results, the moment-rotation relationship of different mortise-tenon joints was obtained, corresponding to the three stages of the elastic stage, yielding stage and failure stage of mortisetenon joints under low-cycle cyclic loading. The moment hinges, axial force hinges, and shear hinges were inserted into the ends of the horizontal members, and axial loadmoment hinges (PMM) and shear hinges were inserted into the vertical members. Considering that the shear failure of wood is brittle failure, the default steel shear hinge provided by SAP2000 is still applicable. The recommended steel axial force hinges and moment hinges in SAP2000 are calculated according to Eqs. (2) and (3):

$$
\begin{aligned}
& P_{\mathrm{y}}=\sigma_{\mathrm{y}} A, u_{\mathrm{y}}=\frac{\sigma_{\mathrm{y}} l}{E}, \\
& M_{\mathrm{y}}=\sigma_{\mathrm{y}} Z, \theta_{\mathrm{y}}=\frac{Z \sigma_{\mathrm{y}} l}{6 E I},
\end{aligned}
$$

where $P_{\mathrm{y}}$ is the yield force of the section, $M_{\mathrm{y}}$ is the yield moment of the section, $u_{\mathrm{y}}$ is the yield displacement of the axial hinge, $\theta_{\mathrm{y}}$ is the yield rotation of moment hinge, $\sigma_{\mathrm{y}}$ is the yield stress of material, $A$ is the section area, $Z$ is the plastic modulus, $I$ is the inertial moment of the section, $l$ is the length of the component, and $E$ is the material elastic modulus.

The force-displacement curve based on Fig. 14b and Table 4 was used to modify the timber axial force hinges, as reported in Fig. 15a. The hardening behaviour of wood was not considered in compression section $\mathrm{B}^{\prime} \mathrm{C}$, and the axial force of the tension section dropped directly when it exceeded point B. The performance levels of IO, LS and CP defined by FEMA-356 [39] are $40 \%, 80 \%$ and $100 \%$ of the ultimate rotation $\theta_{\mathrm{u}}$, respectively. Based on the above definition and the experimental results, the moment

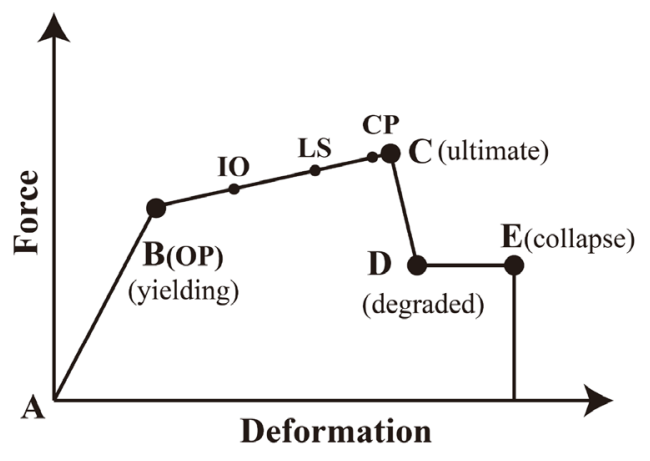

(a) Force-displacement relationship and performance levels

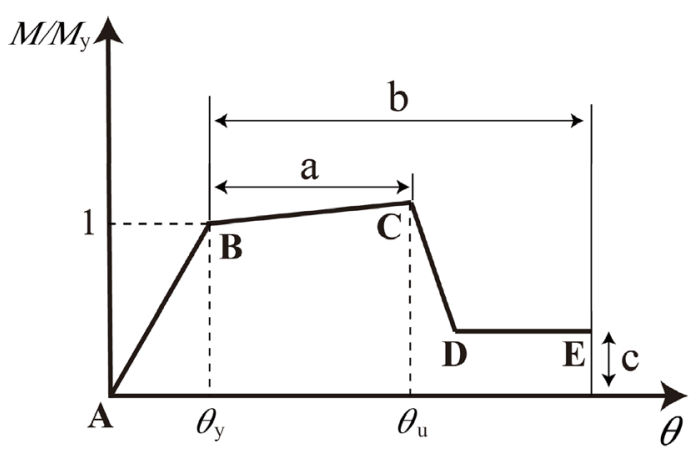

(b) Moment-rotation relationship of a typical plastic mechanism.

Fig. 14 Force-displacement curve and normalized curve of the plastic hinge model 


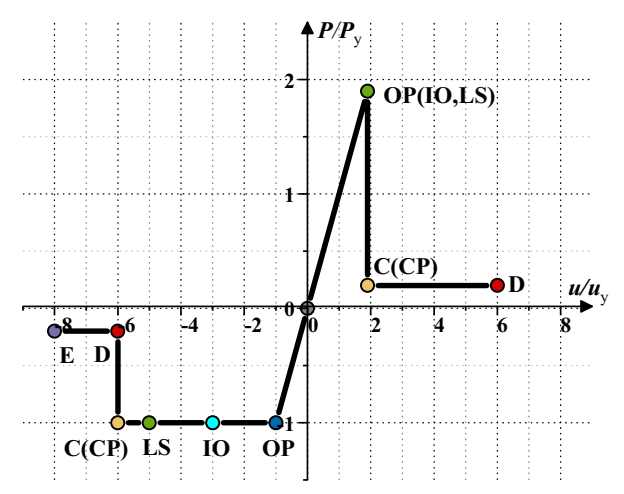

(a) Modification result of axial force hinge

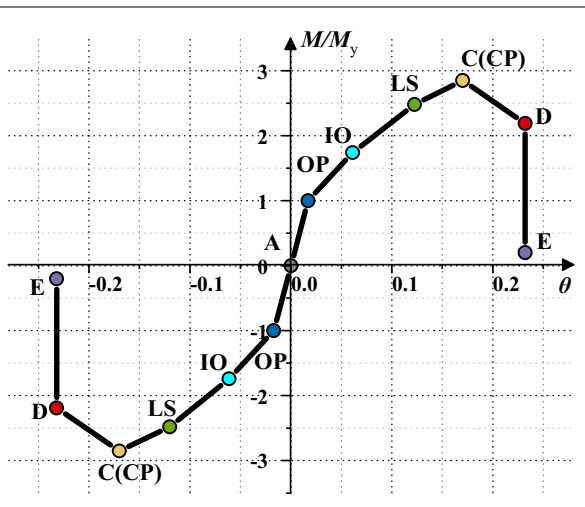

(b) Moment hinge of Beam-NMT

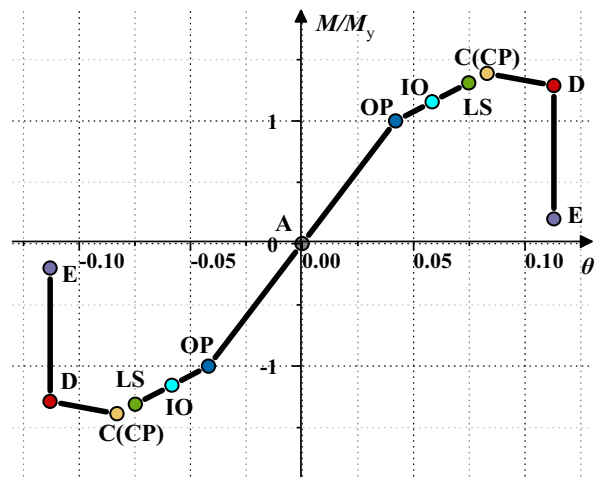

(c) Moment hinge of Beam-TMT

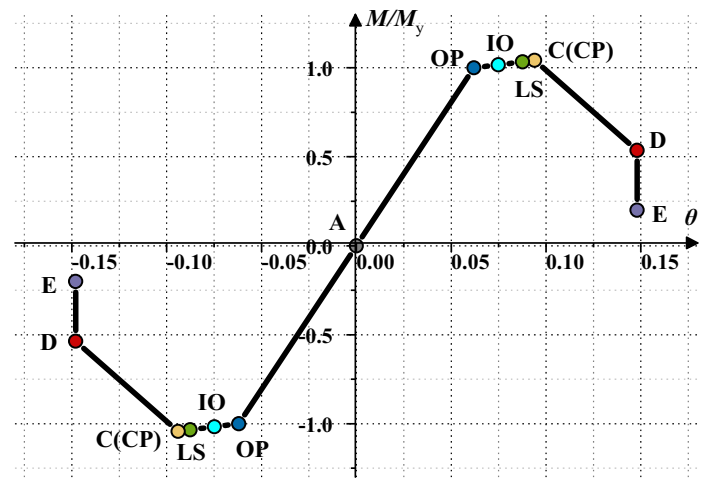

(d) Moment hinge of Beam-SMT

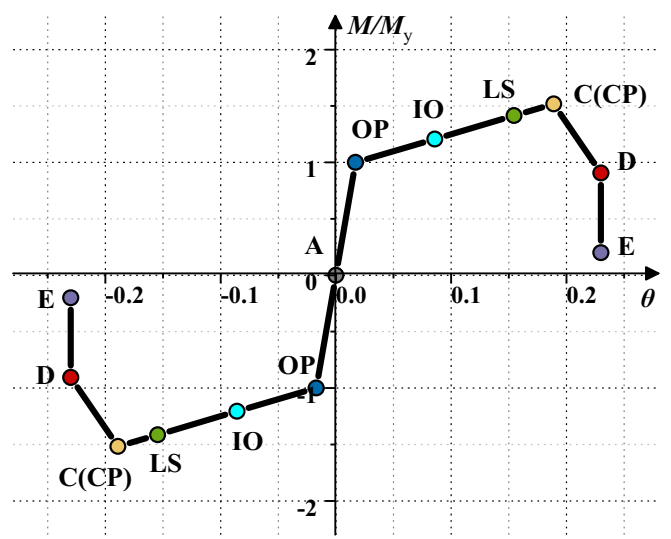

(e) Moment hinge of Beam-SMTM

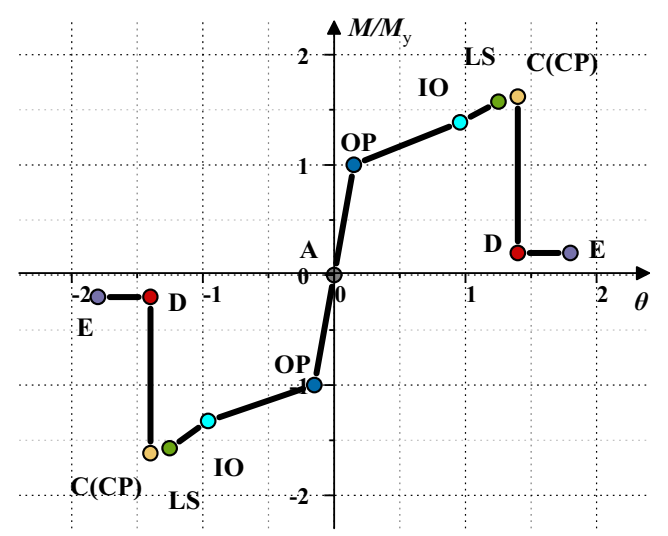

(f) Moment hinge of Beam-M

Fig. 15 The modification of plastic hinges

hinges of the NMT joint, TMT joint, SMT joint, and SMTM joint were adjusted, as shown in Fig. 15b-e. The moment hinges of the remaining sections were modified with reference to the data of the Chinese fir beam experiment [57] (Fig. 15f). The PMM hinges were assigned by default hinge properties provided by the software.

To insert the plastic hinge, the weak components were selected based on the static analysis results of 
Sect. Static analysis. Moment hinges (Beam-M) and shear hinges (Beam-S) were inserted at the ends of the beams to simulate the elastoplastic behaviour caused by the larger bending moment and shear force at the mortise-tenon joints. PMM hinges (Column-PMM) were inserted at each end of the columns to simulate the compression and bending failure. Two-direction shear hinges (Column-V1) and (Column-V2) were inserted into the middle of the columns to simulate shear failure. The plastic hinges of other special mortise-tenon joints are presented in Table 6.

\section{Results of the NSP analysis}

From NSP analysis, the seismic performance will be evaluated from the load-displacement curves of multidegree-of-freedom (MDOF) structure and the capacity curves of idealized single-degree-of-freedom (SDOF) system, and the results of failure sequences of the whole structure.

The relationship between the global base shear and the top displacement is obtained by monotonically applying increasing lateral load until the structure reaches a failure condition; thus, the stiffness and ductility level of the whole structure can be obtained. Lateral load conditions are usually performed after static loads have been applied. There are two patterns of the vertical distribution of lateral loads: modal load pattern and uniform load pattern. Suppose the asymmetric configuration of the main hall leads to a strong coupling effect of the first two modes of horizontal vibration with torsional vibration, and the result of the modal load pattern is more conservative than the result of the uniform load pattern. In that case, the modal loading pattern provided by Eq. (4) is used to act on the vibration direction of the top three modes:

$$
F_{i}=F_{b} \frac{m_{i}\left(\frac{2 \pi}{f_{i}}\right)^{2} u_{i j}}{\sum m_{i}\left(\frac{2 \pi}{f_{i}}\right)^{2} u_{i}},
$$

where $F_{i}$ is the generalized force or displacement imposed on node $i, F_{\mathrm{b}}$ is the total lateral force, $u_{i j}$ is the displacement of the $j$ th mode, $f_{i}$ is the angular frequency of the $j$ th mode, $m_{i}$ is the mass of node $i$, and $i, j=1,2,3 \ldots$

The NSP analysis was performed in two orthogonal directions ( $\mathrm{X}$ and $\mathrm{Y}$ ) and an oblique direction $(0.5 \mathrm{X}+0.5 \mathrm{Y})$, and a total of five working conditions were carried out. Since the elastoplastic behaviour of the material is incorporated with a nonlinear force deformation constitutive relationship of the elements in SAP2000, the P-delta effect is also considered. Node 702 at the east end of the ridge purlin is selected as the monitoring point of the $\pm \mathrm{X}$-direction and oblique direction, and node 793 at the middle of the ridge purlin is selected as the monitoring point of $\pm \mathrm{Y}$.

The pushover curves of the $\pm \mathrm{X}$-direction (mode1 ), \pm Y-direction (mode-2), and XY-direction (first and second mode coupling) are reported in Fig. 16. Compared with the curves of the \pm X-direction and the XYdirection, the stiffness of the Y-direction is approximately six times that of the X-direction and four times that of the XY-direction. It is evident that the asymmetric

Table 6 Plastic hinges of mortise-tenon joints

\begin{tabular}{|c|c|c|c|c|c|}
\hline $\begin{array}{l}\text { Types of } \\
\text { mortise-tenon } \\
\text { joints }\end{array}$ & Component & Insert connection & Types of Plastic hinges & Failure control & Data sources \\
\hline \multirow[t]{4}{*}{ NMT joint } & \multirow{2}{*}{$\begin{array}{l}\text { Upper double-eave-archi- } \\
\text { trave/single-eave-architraves }\end{array}$} & \multirow[t]{2}{*}{ With eave-column } & Beam-NM & Displacement & Figure 15b \\
\hline & & & Beam-MT-V & Default hinge & Automatic calculation \\
\hline & \multirow[t]{2}{*}{ Chuan/tie beam } & \multirow[t]{2}{*}{ With central column } & Beam-NM & Displacement & Figure $15 b$ \\
\hline & & & Beam-MT-V & Default hinge & Automatic calculation \\
\hline \multirow[t]{2}{*}{ TMT joint } & \multirow[t]{2}{*}{ Chuan } & \multirow[t]{2}{*}{ With central column } & Beam-TM & Displacement & Figure $15 d$ \\
\hline & & & Beam-MT-V & Default hinge & Automatic calculation \\
\hline \multirow[t]{3}{*}{ SMT joint } & Lower double-eave-architrave & With eave-column & (Beam-SM) & Displacement & Figure $15 \mathrm{c}$ \\
\hline & $\begin{array}{l}\text { 1-purlin beam, } \\
\text { 2-purlin beam }\end{array}$ & With column & Beam-MT-V & Default hinge & Automatic calculation \\
\hline & 3-purlin beam & With central column & & & \\
\hline \multirow[t]{2}{*}{ SMTM joint } & \multirow[t]{2}{*}{ Melon column } & \multirow{2}{*}{$\begin{array}{l}\text { With 2-purlin beam/intermedi- } \\
\text { ate purlin }\end{array}$} & Beam-GZS & Displacement & Figure $15 \mathrm{e}$ \\
\hline & & & Beam-MT-V & Default hinge & Automatic calculation \\
\hline \multirow[t]{2}{*}{ Normal joints } & Purlin & \multirow[t]{2}{*}{ With incline struts of Dou-gong } & Beam-M & Displacement & Figure 15(f) \\
\hline & Sufang & & Beam-V & Default hinge & Automatic calculation \\
\hline
\end{tabular}




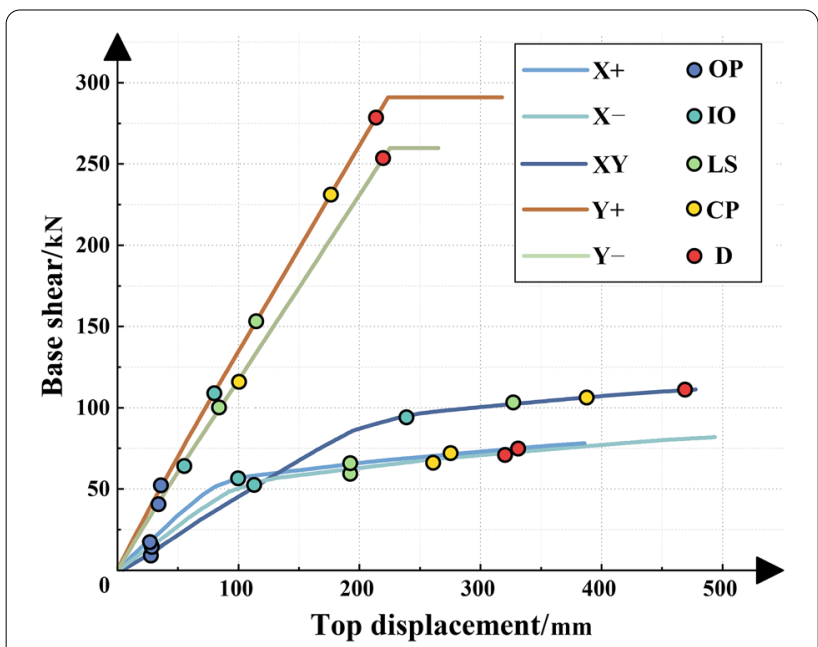

Fig. 16 Nonlinear force-displacement relationship of the main hall

configuration is the main influencing factor of the different lateral behaviour in the $\mathrm{X} / \mathrm{Y}$-direction.

The building presents symmetrical construction in the $\mathrm{X}$-direction, so the stiffness difference in the $\mathrm{X} \pm$ direction is small. Under the $\mathrm{X}+$ loading condition, when the top displacement reaches $117 \mathrm{~mm}$ and the base shear force reaches $53.50 \mathrm{kN}$, the structure has entered the yield stage; when the top displacement reaches $492.65 \mathrm{~mm}$ and the base shear force reaches $78.11 \mathrm{kN}$, many plastic hinges have occurred, and the structure finally collapses. Under the X-loading condition, as the top displacement reaches $105 \mathrm{~mm}$ and the base shear force reaches 50.16 $\mathrm{kN}$, the structure is obviously in the yield stage, while the top displacement reaches $493.52 \mathrm{~mm}$ and the base shear force reaches $75.21 \mathrm{kN}$, the structure overturns. The bearing capacity of the $\mathrm{Y} \pm$ direction is larger than that of the $\mathrm{X} \pm$ direction, but the ductility is smaller. When overall overturning occurs, the structure has not reached the ultimate bearing capacity, but many plastic hinges lead to the final failure of the structure. The bearing capacity of the $\mathrm{Y}+$ direction is slightly larger than that of the Y-direction for the asymmetrical pattern in the depth direction. When the $\mathrm{Y}+$ direction loading condition fails, the top displacement is $223 \mathrm{~mm}$, and the base shear force is $290.09 \mathrm{kN}$. The top displacement of the Y-direction is $211 \mathrm{~mm}$, and the base shear force is $250.97 \mathrm{kN}$. The stiffness in the oblique direction is slightly higher than that in the $\mathrm{X} \pm$ direction, the maximum top displacement is $178.79 \mathrm{~mm}$, and the maximum base shear force is 112.21 $\mathrm{kN}$. In summary, the early hall-style timber structure is susceptible to earthquakes acting in the X-direction, but the structure in the width-direction has greater ductility. Even if there is a large displacement, the structure can remain in plastic state before it is completely overturned.

\section{Capacity spectrum method}

The CSM method proposed in ATC-40 [38] has been applied to compute the performance levels of the main hall. By transforming the pushover curve and the local demand spectrum curve to acceleration-displacement response spectra, the intersection of the two curves as the performance point will be graphically obtained, which represents the acceptance criteria of structure capacity and target seismic demand as defined by local codes.

The obtained pushover curves of MDOF system in Sect. Results of the NSP analysis are converted to acceleration-displacement response spectrum of equivalent SDOF system by Eqs. 5-8:

$$
\begin{aligned}
& S_{\mathrm{ae}}=\frac{V_{\mathrm{e}} / G}{\mu_{j}}, \\
& S_{\mathrm{de}}=\frac{\Delta_{\mathrm{roof}}}{\kappa_{j} X_{j, \text { roof }}}, \\
& \mu_{j}=\frac{\left[\sum m \varphi_{j}\right]^{2}}{m\left[\sum m \varphi_{j}^{2}\right]}, \\
& \kappa_{j}=\frac{\sum m \varphi_{j}}{m\left[\sum m \varphi_{j}\right]^{2}},
\end{aligned}
$$

where $S_{\text {ae }}$ is the spectral acceleration converted by the corresponding base shear value and $S_{\mathrm{de}}$ is the spectral displacement converted by the corresponding top displacement. $V_{\mathrm{e}}$ is an arbitrarily selected point on the pushover curve, $G$ is the gravity load of the structure, $\mu_{j}$ is the mass participation factor of the $j$ th mode, $\Delta_{\text {roof }}$ is the top displacement corresponding to $V_{\mathrm{e}}, \kappa_{j}$ is the modal participation factor of $j$ th mode, $X_{j \text {,roof }}$ is the vertex amplitude of $j$ th mode, $m$ is the mass of the structure, $\varphi_{j}$ is the amplitude of $j$ th mode. The structural height of equilibrium SDOF system is shown in Fig. 11c.

The demand spectrum curves are based on GB 500112010[55] and GB 18306-2015 [58]. The seismic precautionary intensity of the main hall of Baoguo Temple in Ningbo, Zhejiang Province is intensity 7, the soil condition is a moderate-hard soil, which was classified of category II, corresponding to a wave propagation velocity ranging from $250 \mathrm{~m} / \mathrm{s}$ to $500 \mathrm{~m} / \mathrm{s}$. Since the main hall is built on the flat stone platform rather than other unfavourable terrain, the effect of subsoil and topographic amplification is not required to consider in this research, the soil factor is 1. The value of characteristic period $T_{\mathrm{g}}$ which also depends on the soil condition is $0.35 \mathrm{~s}$, together with the definition of peak ground acceleration (PGA) with a return period of 


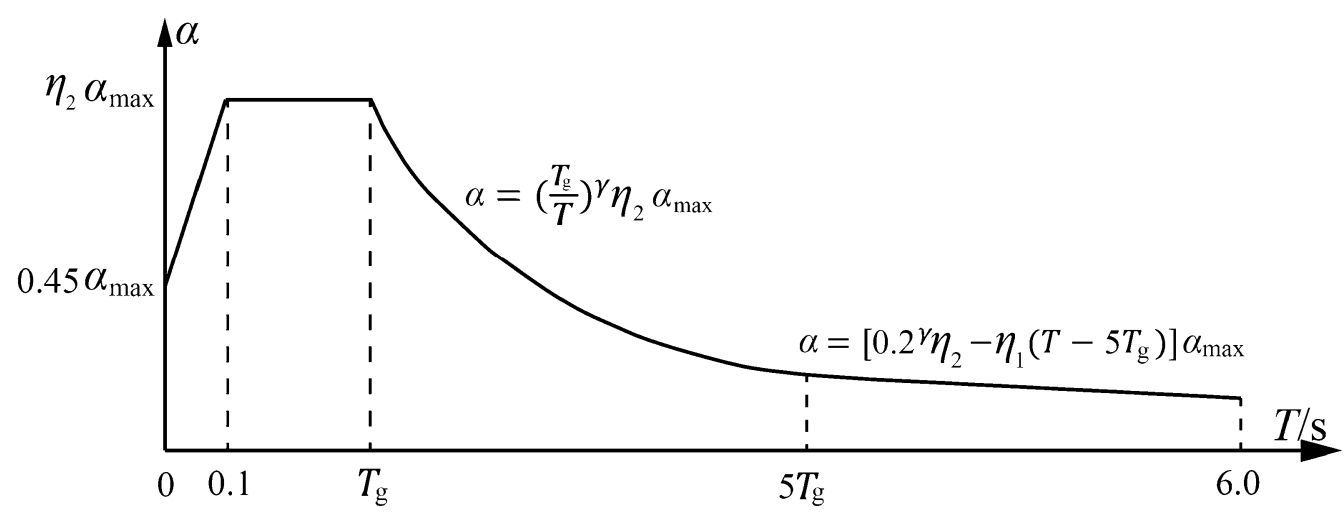

Fig. 17 Seismic influence coefficient curve in the code [55]

50 years, namely, $0.1 \mathrm{~g}$ (PGA of fortification earthquake of intensity 7), $0.2 \mathrm{~g}$ (PGA of moderate earthquake of intensity 7) and $0.3 \mathrm{~g}$ (PGA of severe earthquake of intensity 7) have also been selected to obtain the seismic behaviour of the main hall. The seismic influence coefficient curve is shown in Fig. 17 and the calculation process is defined as Eq. 9Eq. 12 [55]:

$$
\begin{aligned}
& \alpha=\left[0.45+10\left(\eta_{2}-0.45\right) T\right] \alpha_{\max } \quad(0<T \leq 0.1 \mathrm{~s}), \\
& \alpha=\eta_{2} \alpha_{\max } \quad\left(0.1 \mathrm{~s}<T \leq T_{\mathrm{g}}\right), \\
& \alpha=\left[\left(\frac{T}{T_{\mathrm{g}}}\right)^{\gamma} \eta_{2}\right] \alpha_{\max } \quad\left(T_{\mathrm{g}}<T<5 T_{\mathrm{g}}\right), \\
& \alpha=\left[0.2^{\gamma} \eta_{2}-\eta_{1}\left(T-5 T_{\mathrm{g}}\right)\right] \alpha_{\max } \quad\left(5 T_{\mathrm{g}}<T \leq 6 \mathrm{~s}\right),
\end{aligned}
$$

where $\alpha$ is the seismic influence coefficient and $\alpha_{\max }$ is the maximum value of seismic influence coefficient. $\gamma$ is the attenuation index of curvilinear descending section, $\gamma=0.9+(0.05-\xi) /(0.5+5 \xi)$. $\xi$ is the fixed damp ratio of the structure, the value of which is set 0.05. $\eta_{1}$ is the modification factor of the descending slope in the linear decreasing region, $\eta_{1}=0.02+(0.05-\xi) /(4+32 \xi) . \eta_{2}$ is the damping modification factor, $\eta_{2}=1+(0.05-\xi) /(0.08+1.6 \xi)$

The transformation local elastic demand spectra are then transformed to acceleration-displacement response spectrum with a damping modification factor by Eqs. 13-16 [33]:

$$
S_{\mathrm{de}}=S_{\mathrm{ae}} \frac{T_{e}^{2}}{4 \pi^{2}} g,
$$

$$
\begin{aligned}
& S_{\mathrm{ae}}=\left\{\begin{array}{l}
\alpha \mathrm{SR}_{\mathrm{A}}\left(0.1 s<T \leq T_{\mathrm{g}}\right) \\
\alpha \mathrm{SR}_{\mathrm{V}}\left(T_{\mathrm{g}}<T \leq 5 T_{\mathrm{g}}\right)
\end{array}\right. \\
& S R_{\mathrm{A}}=\frac{3.21-0.68 \ln \left(\beta_{\mathrm{eff}}\right)}{2.12}, \\
& S R_{\mathrm{V}}=\frac{2.31-0.41 \ln \left(\beta_{\mathrm{eff}}\right)}{1.65},
\end{aligned}
$$

where $S_{\mathrm{de}}$ is the spectrum displacement to the corresponding acceleration $S_{\mathrm{ae}}$ at the period $T_{\mathrm{e}}$ in the demand spectrum. $S R_{\mathrm{A}}$ is the reduction factor of the demand spectrum at the section of $0.1 \mathrm{~s}<T \leq T_{\mathrm{g}}, S R_{\mathrm{V}}$ is the reduction factor of the demand spectrum at the section of $T_{\mathrm{g}}$ $<T \leq 5 T_{\mathrm{g}}, \beta_{\mathrm{eff}}$ is the equivalent viscous damping of the structure, which consists of the fixed viscous damping and hysteretic damping of the structure, taking the value of $5,10,15$ in this research.

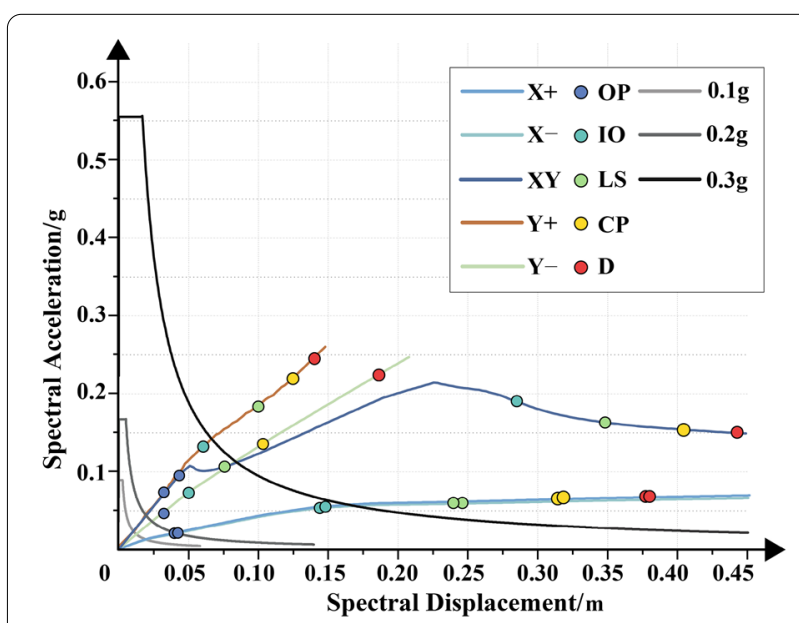

Fig. 18 Acceleration-displacement curves of capacity spectrum method 
From the calculated results of the CSM method in Fig. 18, the structure in different loading cases is safe under $0.1 \mathrm{~g}$ and $0.2 \mathrm{~g}$ peak ground acceleration, for the spectrum displacement is less than the ultimate displacement requirements in code [55] and the whole structure is in OP stage. The seismic response of X-direction is rather ductile than Y-direction, however, the maximum spectrum acceleration is in a range between $0.05 \mathrm{~g}$ and $0.07 \mathrm{~g}$. The structure is not completely destroyed until a large spectrum displacement is reached, but remains in yield state, which indicates the building is vulnerable to damage when subjected to earthquakes in the widthdirection. At the peak ground acceleration of $0.3 \mathrm{~g}$, all five loading cases enter IO stage before reaching the performance point, and in Y-direction, the structure is in LS stage and will quickly enter the $\mathrm{CP}$ stage, which means that the Y-direction will be more susceptible to damage in severe earthquake.

The inter-storey drift angle is usually selected as the seismic demand parameter to reflect structural responses under earthquake excitation, in this research, the interstorey drift angle of the global structure is calculated as Eq. 17:

$$
\theta_{i}=\frac{\Delta_{2}-\Delta_{1}}{H},
$$

where $\theta_{i}$ is the inter-storey drift angle of the hall-style timber frame, $\Delta_{1}$ is the absolute displacement of the node in the column foot. $\Delta_{2}$ is the absolute displacement of the monitoring point. $H$ is the heights of the timber frame.

According to the calculation, the performance point is shown in Fig. 18, and the inter-storey drift angles of the structure under the action of $0.1 \mathrm{~g}, 0.2 \mathrm{~g}$, and $0.3 \mathrm{~g}$ peak ground acceleration are shown in Table 7 . Referring to the Chinese standard [55] and shaking table experimental research [59], the maximum inter-storey drift angle of the ancient timber structure in the elastic stage is $1 / 250$, and the maximum inter-storey drift angle is $1 / 48$ in the elastoplastic stage. As shown in Table 7, under acceleration conditions of $0.1 \mathrm{~g}$ and $0.2 \mathrm{~g}$, the inter-storey drift angles of the building under the five loading conditions are all less than $1 / 250$. Nevertheless, at an exaction of $0.3 \mathrm{~g}$, the inter-storey drift angle is larger than $1 / 250$ but less than $1 / 48$. The results above indicate that excellent lateral resistance still existed when subjected to moderate earthquake, but there remains high risk of the building when responding to high-intensity earthquake excitations.

The time history analysis considering maximum ground acceleration in NSP analysis is performed to compare with the results of pushover analysis. The El Centro wave is selected to act in the east-west direction, that is, in the X-direction, and the first $20 \mathrm{~s}$ is intercepted for time history analysis with a total of 1000 load steps; the time interval is $0.02 \mathrm{~s}$. Based on the analysis in Sect. Static analysis, 11 typical nodes of the structure are selected for observation, the maximum displacement of each node under the action of $0.3 \mathrm{~g}$ ground acceleration is shown in Table 8. The maximum displacement of $88.75 \mathrm{~mm}$ occurs at node 702 , which is consistent with the $\mathrm{X}$-direction monitoring point in pushover analysis. Therefore, pushover analysis can obtain a more conservative result. The inter-storey drift angles of the 11 nodes are consistent with the results obtained by the capacity spectrum method, and they are all less than $1 / 48$ with little difference in values.

Table 8 Displacement response results

\begin{tabular}{llll}
\hline Components & Node & $\boldsymbol{u}_{\mathbf{y m a x}} / \mathbf{m m}$ & $\boldsymbol{\Delta / H}$ \\
\hline Southern architraves & 347 & 61.05 & $1 / 160$ \\
Western architraves & 128 & 85.68 & $1 / 114$ \\
Ridged purlin & 702 & 88.75 & $1 / 110$ \\
& 793 & 86.46 & $1 / 113$ \\
& 713 & 87.95 & $1 / 111$ \\
Intermediate purlin A & 775 & 84.40 & $1 / 115$ \\
& 738 & 83.94 & $1 / 116$ \\
Intermediate purlin C & 699 & 85.81 & $1 / 114$ \\
Inner architraves & 451 & 84.26 & $1 / 116$ \\
& 492 & 85.13 & $1 / 114$ \\
\hline
\end{tabular}

Table 7 The results of capacity spectrum method

\begin{tabular}{|c|c|c|c|c|c|c|c|c|c|c|}
\hline \multirow[t]{3}{*}{$a_{\mathrm{g}}(\mathrm{g})$} & \multicolumn{10}{|c|}{ Direction } \\
\hline & \multicolumn{2}{|l|}{$x+$} & \multicolumn{2}{|l|}{$X-$} & \multicolumn{2}{|l|}{$\mathrm{Y}+$} & \multicolumn{2}{|l|}{$\mathrm{Y}-$} & \multicolumn{2}{|l|}{$X Y$} \\
\hline & $\begin{array}{l}u_{\mathrm{y}} / \\
\mathrm{mm}\end{array}$ & $\Delta / H$ & $\begin{array}{l}u_{\mathrm{y}} / \\
\mathrm{mm}\end{array}$ & $\Delta / H$ & $\begin{array}{l}u_{\mathrm{y}} / \\
\mathrm{mm}\end{array}$ & $\Delta / H$ & $\begin{array}{l}u_{\mathrm{y}} / \\
\mathrm{mm}\end{array}$ & $\Delta / H$ & $\begin{array}{l}u_{\mathrm{y}} / \\
\mathrm{mm}\end{array}$ & $\Delta / H$ \\
\hline 0.1 & 12.03 & $1 / 813$ & 11.59 & $1 / 844$ & 10.55 & $1 / 927$ & 15.72 & $1 / 622$ & 4.98 & $1 / 1965$ \\
\hline 0.2 & 22.27 & $1 / 439$ & 21.98 & $1 / 445$ & 21.98 & $1 / 445$ & 27.02 & $1 / 362$ & 9.18 & $1 / 1065$ \\
\hline 0.3 & 95.67 & $1 / 102$ & 95.89 & $1 / 102$ & 77.01 & $1 / 127$ & 82.18 & $1 / 119$ & 29.19 & $1 / 335$ \\
\hline
\end{tabular}




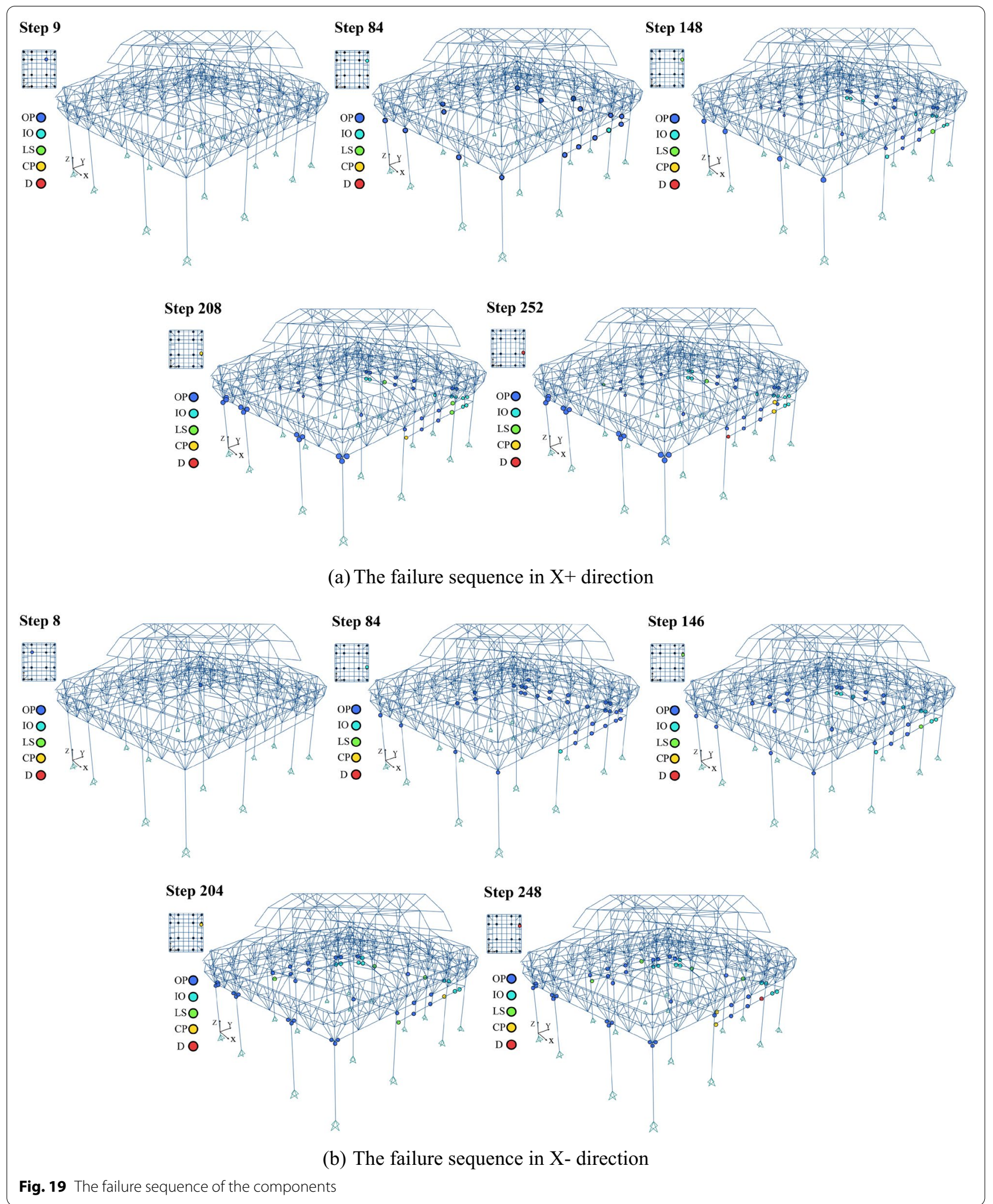




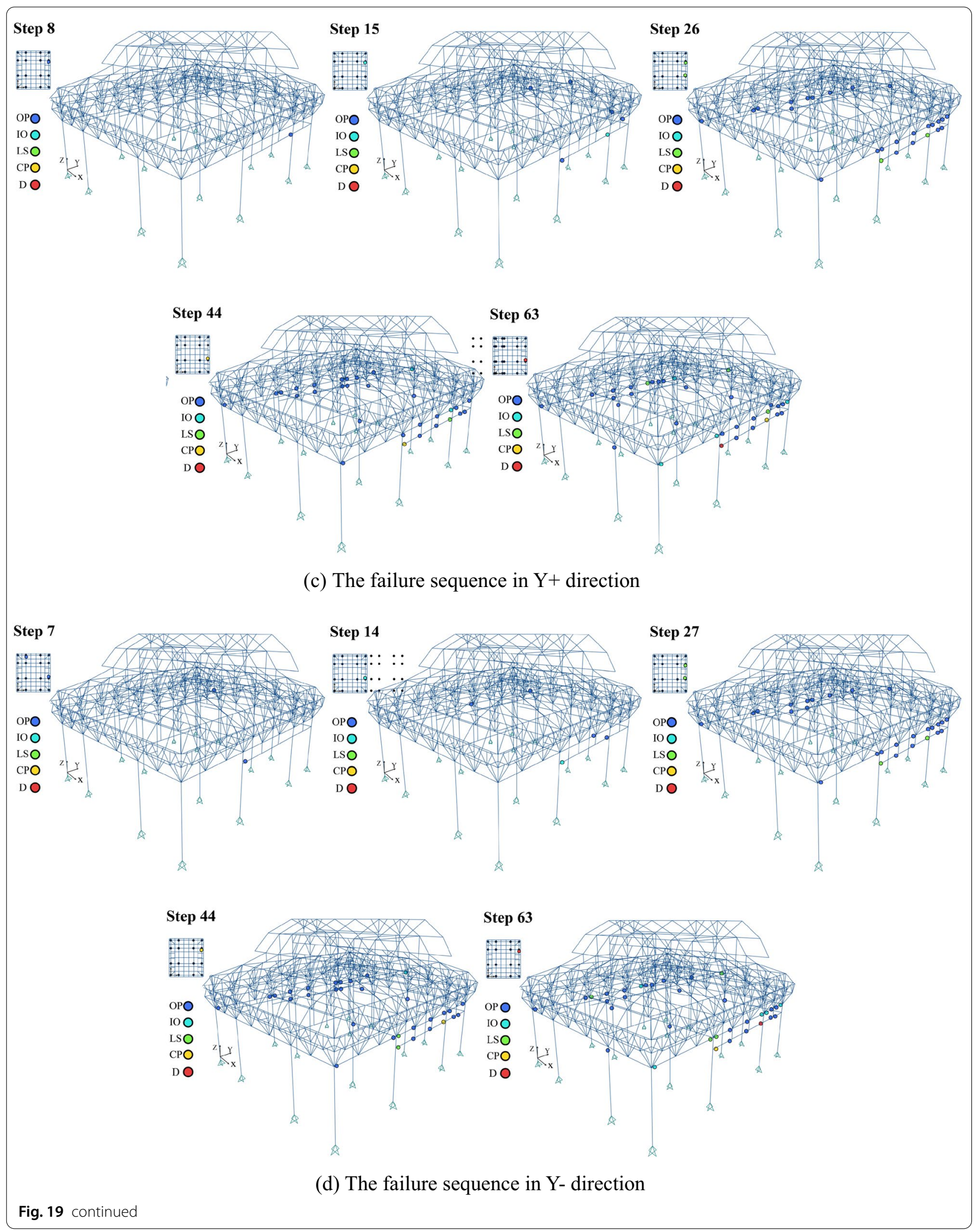




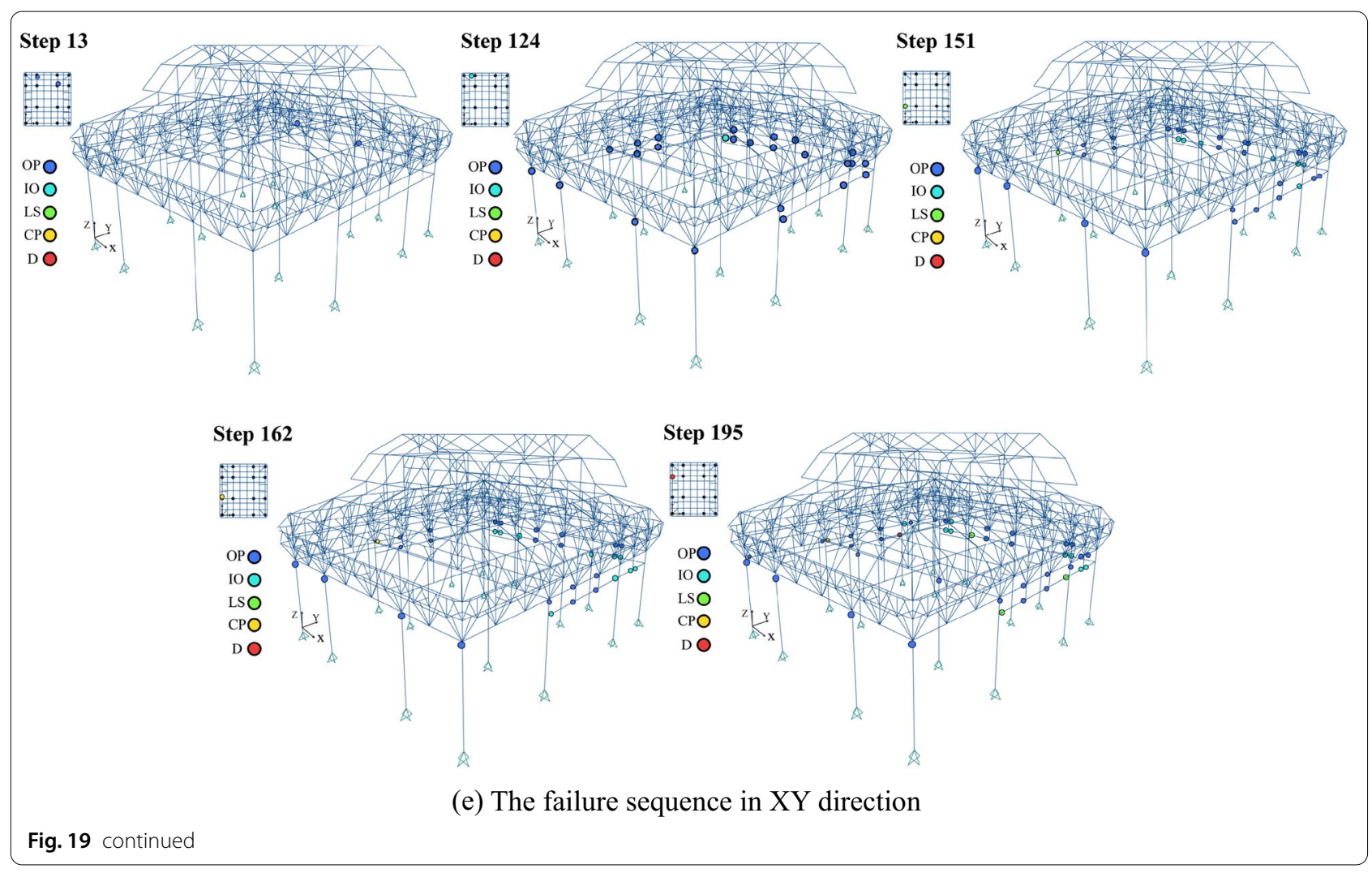

\section{Failure sequence of the hall-style timber frame}

The failure sequence of components is a gradual development process, and the seismic performance of the structure is closely related to the failure modes of the structure. As shown in Fig. 19a, b, the first appearance of the OP hinge in the $\mathrm{X} \pm$ direction is at the end of the 2-purlin beams with the connection to the inner columns $\mathrm{C} 21$ and C22. Then, double-eave-architrave on both the east sides of the structure begin to generate IO plastic hinges, while eave-column SW to SE, with single eavearchitrave configuration, also began to appear OP plastic hinges caused by the bending of the column head. The plastic hinge gradually develops along the double-eavearchitrave, with some OP hinge start to appear on the head of W1 to E1 columns. In the later stage of loading, the first appearance of LS, CP hinge are all at the connection of the east double-eave-architrave and the eavecolumn. The plastic hinges in this area finally reach the ultimate bearing capacity, causing the structure to overturn.

In the $\mathrm{Y} \pm$ direction (Fig. 19c, d), OP hinges are produced and quickly developed in the lower components of double-eave-architrave connected column E1 to column NE. Different from the loading cases of X-direction, Chuan components connected the central columns with NMT joints begin to generate OP hinge in the early stage
Table 9 Inter-storey drift angles corresponding to different performance levels under five loading cases

\begin{tabular}{|c|c|c|c|c|c|}
\hline Loading case & Performance level & OP & 10 & LS & $\mathrm{CP}$ \\
\hline \multirow[t]{4}{*}{$(x+)$} & Step & 9 & 84 & 148 & 208 \\
\hline & Displacement/mm & 34.26 & 115.38 & 197.19 & 272.15 \\
\hline & Base force/kN & 9.72 & 53.02 & 61.52 & 66.82 \\
\hline & $\Delta x+/ H$ & $2 / 571$ & $4 / 339$ & $5 / 248$ & $16 / 575$ \\
\hline \multirow[t]{4}{*}{$(x-)$} & Step & 8 & 84 & 146 & 204 \\
\hline & Displacement/mm & 39.74 & 115.80 & 193.41 & 265.95 \\
\hline & Base force/kN & 7.97 & 52.21 & 60.06 & 67.74 \\
\hline & $\Delta_{\mathrm{X}-} / H$ & $1 / 246$ & $11 / 929$ & $7 / 354$ & $22 / 809$ \\
\hline \multirow[t]{4}{*}{$(Y+)$} & Step & 8 & 15 & 26 & 44 \\
\hline & Displacement/mm & 36.21 & 80.83 & 125.85 & 173.43 \\
\hline & Base force/kN & 55.79 & 112.05 & 168.10 & 228.47 \\
\hline & $\Delta_{Y+} / H$ & $1 / 270$ & $1 / 121$ & $7 / 544$ & $5 / 282$ \\
\hline \multirow[t]{4}{*}{$(\mathrm{Y}-)$} & Step & 7 & 14 & 27 & 44 \\
\hline & Displacement/mm & 33.51 & 54.38 & 86.89 & 101.90 \\
\hline & Base force/kN & 39.47 & 63.01 & 101.17 & 116.5 \\
\hline & $\Delta_{Y-} / H$ & $1 / 292$ & $1 / 180$ & $7 / 788$ & $1 / 96$ \\
\hline \multirow[t]{4}{*}{$(X Y)$} & Step & 13 & 124 & 151 & 162 \\
\hline & Displacement/mm & 32.75 & 247.91 & 335.95 & 371.80 \\
\hline & Base force/kN & 15.85 & 97.11 & 103.64 & 106.13 \\
\hline & $\Delta X Y / H$ & $3 / 896$ & $20 / 789$ & $9 / 262$ & $23 / 605$ \\
\hline
\end{tabular}


Table 10 Reference index for inter-storey drift angle of each performance level

\begin{tabular}{llllll}
\hline Performance levels & OP & IO & LS & CP & C \\
\hline Revised Drift ratio & $\Delta / H \leq 1 / 300$ & $1 / 300 \leq \Delta / H \leq 1 / 180$ & $1 / 180 \leq \Delta / H \leq 1 / 115$ & $1 / 115 \leq \Delta / H \leq 1 / 95$ & $\Delta / H \geq 1 / 95$ \\
$\begin{array}{l}\text { Drift ratio suggested by } \\
\text { the codes }\end{array}$ & $\Delta / H \leq 1 / 250$ & $1 / 250 \leq \Delta / H \leq 1 / 125$ & $1 / 125 \leq \Delta / H \leq 2 / 125$ & $2 / 125 \leq \Delta / H \leq 3 / 160$ & $\Delta / H \geq 1 / 48$ \\
\hline
\end{tabular}

of loading. However, LS, CP hinges both appear firstly at the end of the eastern double-eave-architrave, representing the same phenomenon as X-direction loading. In the later stage, a variety of OP hinges have appeared on the head of the middle columns, double-eave-architrave in both east and west sides suffer severe damage.

Under the XY-oblique-direction, the first OP hinge appeared in the middle part of intermediate purlin C. Later, amount of OP hinges appear on the western and eastern double-eave-architrave and the head of front eave columns, then these OP hinges change to LS and $\mathrm{CP}$ stage. The OP hinges on the head of central columns generate in the final stage of loading, and the failure is of ultimate bearing capacity caused by many plastic hinges (Fig. 19e).

Based on the above analysis, it can be concluded that due to the stiffness asymmetry, the eave-column on the east side of the main hall are more likely to be destroyed than the eave-column on the other three sides. For the double-eave-architrave configuration, more plastic hinges appeared on the lower-eave-architrave with beamSMT plastic hinge. NMT joints have higher rigidity relative to SMT joints. The plastic hinges are almost not in the central area under X-direction and XY-direction loading, which can indicate that the application of reinforcing timber components plays an important role in strengthening the internal rigidity.

\section{Definition of seismic performance level}

Both the Chinese Seismic Standard and FEMA-356 use the inter-storey drift angle to define the seismic performance index. According to the calculated results of the pushover analysis in Sect. Failure sequence of the hallstyle timber frame, inter-storey drift angles corresponding to different performance levels under five loading conditions are defined in Table 9.

Table 9 Inter-storey drift angles corresponding to different performance levels under five.

As shown in Table 9, when the performance level reaches $\mathrm{CP}$ in the $\mathrm{X}$-direction, it is already close to the maximum elastic deformation values defined by the specification. Although the structural stiffness of the Y-direction is relatively large, the displacement still does not reach the specification limit value when the global failure occurs. The XY-oblique-direction rigidity is weaker, but the ductility is stronger than the Y-direction rigidity, and the inter-storey drift angle under all performance levels have obviously exceeded the limit value. Considering that the architectural heritage of the Song and Yuan dynasties has a history of more than 1000 years, the degradation of material strength and the damage of components are more severe than other buildings, and the code has a relatively loose limit for elastoplastic deformation, which is not suitable for seismic analysis of hall-style timber frames. Based on the above calculation results, the reference value of the seismic performance levels of the hall-style timber frame should be revised, as shown in Table 10.

Table 10 Reference index for inter-storey drift angle of each performance level.

\section{Conclusions}

In this research, the seismic performance of hall-style timber frames in the Song and Yuan dynasties is investigated by NSP analysis with performance-based seismic evaluation method to obtain the seismic response of hallstyle timber structures. A simplified finite element model for typical research case has been established through actual configuration analysis and in situ measurement data. The timber plastic hinges are modified based on the low-cycle cyclic load test data of four different mortise-tenon joints to simulate the elastoplastic behaviours of the hall-style timber frame. The performance assessment method of the main hall is displayed with charts and comparatively evaluated with current codes and time history analysis. The conclusions drawn from this article are summarized as follows:

(1) Compared to other ancient timber structures, construction methods are conducive in increasing the integrity of the whole structure: main load-bearing beams and columns intersect directly by the mortise-tenon joints instead of Dou-gong set; the hallstyle building is usually a square plane with the width:depth:height ratio is close to $1: 1: 1$, indicating that the global structure can be regarded as an idealized single-degree-of-freedom system for simulation. More reinforcing timber components were applied to reduce negative effects caused by the dif- 
ferent height of columns. The use of mortise-tenon joints varies according to the mechanical characteristics of the load-bearing members.

(2) The static analysis results illustrate that the vertical deformation of the components, such as purlins, architraves, and melon columns, are relatively large. The modal analysis indicates that the first mode of the structure is $\mathrm{X}$-direction translation with slight torsion, the second mode is Y-direction translation, and the third mode is $\mathrm{Z}$-axis torsion. The asymmetrical configuration in the depth direction, which is widely present in hall-style timber structures, may lead to stiffness asymmetry, causing the structure to be easily affected by torsional vibration.

(3) Based on the moment-rotation relationship of four special mortise-tenon joints, the performance levels of the timber plastic hinges have been revised. The insertion position of the plastic hinges are selected at the mortise-tenon joints and the end of the member with larger vertical deformation under static analysis. As the result of nonlinear static pushover analysis, the ductility of the structure is higher in the width-direction than in other directions, but the results of CSM method show that the maximum spectrum acceleration of width-direction is about $0.05 \mathrm{~g} \sim 0.07 \mathrm{~g}$, which indicates the main hall is vulnerable when suffering earthquakes in the width-direction. In addition, it should be notice that under the influence of ground accelerations of $0.1 \mathrm{~g}, 0.2 \mathrm{~g}$, the displacement of monitoring point and inter-storey drift angle of the main hall is less than ultimate requirements of the codes, but the main hall has the potential to be damaged when subjected to high-intensity seismic excitation.

(4) The failure sequence of the components indicates that the eave-column in the east side of the main hall is more likely to be destroyed than the eavecolumn on the other three sides due to structural asymmetry. More plastic hinges appeared on the double-eave-architrave than other components in the central bay of the timber structure, which means that the reinforcing timber components play an important role in strengthening the integral rigidity.

(5) As the calculation results presented in this research, the maximum inter-storey drift angle given by current codes and research is not applicable for the 1000-year history hall-style timber heritage. To provide the prescribed performance levels for hall-style timber structures in the Song and Yuan dynasties (tenth-fourteenth century AD), the performance level is redefined according to the interstorey drift angle values when the corresponding plastic hinge appears for the first time. It should be noted that the internal structure of traditional timber structures exist variable construction method due to limitation of technology at that time, even if the main hall of Baoguo Temple is the architectural prototype of hall-style timber structures, more applicable guidelines should be defined based on a broader case study, which will be further researched in the extending study.

\begin{abstract}
Abbreviations
AD: Anno Domini; NMT joint: Niekougumao Mortise-tenon joint; TMT joint: Tou Mortise-tenon joint; SMT joint: Straight mortise-tenon joint; SMTM joint: Straight mortise-tenon joint at the foot of melon column; OP: Operational; IO: Immediate occupancy; LS: Life safety; CP: Collapse prevention; NSP: Nonlinear static pushover; CSM: Capacity spectrum method; PMM: Axial load-moment hinge; MDOF: Multi-degree-of-freedom; SDOF: Single-degree-of-freedom; PGA: Peak ground acceleration; UX: X-translation direction; UY: Y-translation direction; RZ: Z-rotation direction.
\end{abstract}

\section{Acknowledgements}

Not applicable.

\section{Authors' contributions}

$Y L$ contributed to the methodology, simulation, results analysis, and original draft of this manuscript. QC contributed to the methodology and review of this manuscript. All authors contributed to the scanning and surveying of the temple. All authors read and approved the final manuscript.

\section{Funding}

This study was supported by the National Natural Science Foundation of China (51778122).

\section{Availability of data and materials}

The data used to support the findings of this study are available from the corresponding author upon request.

\section{Declarations}

\section{Competing interests}

The authors declare that they have no competing interests. Informed consent was obtained from all individual participants included in the study.

Received: 6 July 2021 Accepted: 19 December 2021

Published online: 03 January 2022

References

1. Meng X, Yang Q, Wei J, Li T (2018) Experimental investigation on the lateral structural performance of a traditional Chinese pre-Ming dynasty timber structure based on half-scale pseudo-static tests. Eng Struct 167:582-591. https://doi.org/10.1016/j.engstruct.2018.04.077

2. Chen L, Li S, Wang Y, Zhao Y, Zhang M, Song X, Li X, Wu T, Jiang Z (2017) Experimental study on the seismic behaviour of mortise-tenon joints of the ancient timbers. Struct Eng Int 27(4):512-519. https://doi.org/10. 2749/222137917x14881937844720

3. Zhang X, Wu C, Xue J, Ma H (2019) Fast nonlinear analysis of traditional Chinese timber-frame building with Dou-Gon. Int J Archit Herit 14(8):1252-1268. https://doi.org/10.1080/15583058.2019.1604847

4. Ma H, Luan X, Li Zh, Cui H, Wang W, Song J (2019) Seismic performance of damaged dovetail joints with different damaged degrees in timber frames. Adv Civ Eng. https://doi.org/10.1155/2019/7238217 
5. Xue J, Guo R, Qi L, Xu D (2019) Experimental study on the seismic performance of traditional timber mortise-tenon joints with different looseness under low-cyclic reversed loading. Adv Struct Eng 22:1312-1328. https://doi.org/10.1177/1369433218814167

6. Tanahashi H, Suzuki Y (2020) Review on the mechanical models and formulations of embedment of traditional timber joints in Japan. Jpn Archit Rev 3:148-164. https://doi.org/10.1002/2475-8876.12137

7. Ogawa K, Sasaki Y, Yamasaki M (2015) Theoretical modeling and experimental study of Japanese "Watari-ago" joints. J Wood Sci 61:481-491. https://doi.org/10.1007/s10086-015-1498-3

8. Ogawa K, Sasaki Y, Yamasaki M (2016) Theoretical estimation of the mechanical performance of traditional mortise-tenon joint involving a gap. J Wood Sci 62:242-250. https://doi.org/10.1007/ s10086-016-1544-9

9. Chang W, Hsu M, Komatsu K (2006) Rotational performance of traditional Nuki joints with gap I: theory and verification. J Wood Sci 52:58-62. https://doi.org/10.1007/s10086-005-0734-7

10. Fujita K, Kobayashi Y, Kawahara H, Inayama M, Gotou M (2011) Takahashi K. Moment resisting performance of Japanese traditional wooden joints feature of each joint and presumption of moment resisting performance in cross-type joint. J Struct Constr Eng 76:12991308. https://doi.org/10.3130/aijs.76.1299 (in Japanese)

11. Suesada H, Miyamoto K, Shibusawa T, Aoki K, Inayama M (2019) Reinforcing effect of hardwoods on the moment resistance performance of traditional Japanese "nuki"-column joints. J Wood Sci. https://doi.org/ 10.1186/s10086-019-1844-y

12. Xue J, Wu C, Zhang Y (2020) Analysis of dynamic characteristics and seismic response of a historic roof structure of palace-style timber frame structure. J Build Struct. https://doi.org/10.14006/j.jzjgxb.2019. 0860 (in Chinese)

13. Yeo SY, Komatsu K, Hsu MF, Chung YL, Chang WS (2018) Structural behavior of traditional Dieh-Dou timber main frame. Int J Archit Herit 12:555-577. https://doi.org/10.1080/15583058.2018.1442518

14. Suzuki Y, Maeno M (2006) Structural mechanism of traditional wooden frames by dynamic and static tests. Struct Control Health Monit 13:508-522. https://doi.org/10.1002/stc.153

15. Watanabe T, Miyamoto Y, Suzuki Y (2011) Analysis and simulation of observed seismic records of the traditonal wooden temple, HigashiHonganji Goeidou. AlJ J Technol Des 17:117-122. https://doi.org/10. 3130/aijt.17.117 (in Japanese)

16. Toyoda T, Fujita K, Takano K (2018) Vibration measurement and structural performance evaluation of a 17th century timber guest house in Japan. Jpn Archit Rev 2:16-25. https://doi.org/10.1002/2475-8876. 12062

17. Kinya S (2010) Research on the Zen-style architecture of the early middle age. Central Public Art Press, Tokyo (in Japanese)

18. Zhang S (2002) Buddhist temples of Jiangnan in China. Hubei Education Press, Wuhan (in Chinese)

19. Takahisa S (2006) On the member size in Joudo-do, Joudo-ji: a study on the standardization of the member size in the Daibutsu style Part 3. J Archit Plann, AlJ 71:175-182. https://doi.org/10.3130/aija.71.175_2 (in Japanese)

20. Choi G (2003) A study on Sashihijiki of the wooden bracket in the Korea, China and Japan (2): about the function of Sashihijiki. J Archit Plann 68:343-347. https://doi.org/10.3130/aija.68.343 (in Japanese)

21. Kinya S (1984) Chinese ancient architecture of Zhe Region in Song and Yuan dynasties-2-the wooden relics of Zhejiang Region in Song and Yuan dynasties and Zen-Style architecture in the early middle age. Ars buddhica, Tokyo (in Japanese)

22. Kang S, Yoon C (2016) A Study on the framework schema of JusimpoStyle Buddhist halls of Goryeo period. J Achit Hist 25:7-16. https://doi. org/10.7738/jah.2016.25.6.007 (in Korean)

23. Li J (2011) Yingzaofashi. People's Publishing House, Beijing (in Chinese)

24. Liu J, Cao C, Liu X, Zhang L, Chen B, Li S (2019) The evolution of the timber structure system of the Buddhist buildings in the regions south of the Yangtze River from 10(th)-14(th) century based on the main hall of Baoguo Temple. Int J Archit Herit 13:114-127. https://doi.org/10.1080/ 15583058.2018.1497230

25. Xue J, Zhang F, Zhao H, Ge H, Sui Y, Xie Q (2012) Dynamic analysis model of monolayer hall-style ancient timber structure. J Build Struct 33:135-142. https://doi.org/10.14006/j.jzjgxb.2012.08.016
26. Han Y, Chun Q, Jin H (2021) Wind-induced vibration performance of early Chinese hall-style timber buildings. J Wood Sci. https://doi.org/10.1186/ s10086-020-01939-3

27. Fujita K, Sakamoto I, Ohashi Y (2000) Static and Dynamic Loading Tests of Bracket Complexes Used in Traditional Timber Structures in Japan. In: 12th World Conference on Earthquake Engineering. Auckland: New Zealand Society for Earthquake Engineering.

28. Fujita K (2019) Dynamic performance of bracket complexes used in traditional timber structures in Japan. Proc Jpn Acad Ser B. https://doi.org/10. 2183/pjab.95.038

29. Zhang S (2013) The Cai and Zi forms used in the main hall of Baoguo temple and its internal relationship with "Yingzaofashi." J Chin Archit Hist 1:36-51 (in Chinese)

30. Zhang S (2012) The main hall of Baoguo Temple - survey analysis and fundamental research. Southeast University Press, Nanjing (in Chinese)

31. Chun Q, Lv W, Wang J, Pan J (2015) Mechanical properties of typical mortise-tenon joints of post and lintel construction and column and tie construction of timber buildings in Jiangsu Province and Zhejiang Province. J Southeast Univ (Nat Sci Ed) 45:151-158 (in Chinese)

32. LvW, Chun Q (2015) Experimental study on mechanical properties of typical mortise-tenon joints of ancient traditional timber buildings in Jiangsu and Zhejiang. Build Sci 31:50-56. https://doi.org/10.13614/j.cnki. 11-1962/tu.2015.03.009 (in Chinese)

33. Yin Y, Nagao H, Liu X (2010) Mechanical properties assessment of Cunninghamia lanceolata plantation wood with three acoustic-based nondestructive methods. JWood Sci 56:33-40. https://doi.org/10.1007/ s10086-009-1067-8

34. Standardization Administration of China (2009) GB/T 1936.1-2009 Method of testing in bending strength of wood. Chinese Standards Press, Beijing (in Chinese)

35. Standardization Administration of China (2009) GB/T 1938-2009 Method of testing in tensile strength parallel to grain of wood. Chinese Standards Press, Beijing (in Chinese)

36. Standardization Administration of China (2009) GB/T 1935-2009 Method of testing in compressive strength parallel to grain of wood. Chinese Standards Press, Beijing (in Chinese)

37. Standardization Administration of China (2009) GB/T 1937-2009 Method of testing in shearing strength parallel to grain of wood. Chinese Standards Press, Beijing (in Chinese)

38. Applied Technology Council (1996) Seismic evaluation and retrofit of concrete buildings - technical report ATC-40. Applied Technology Council, Redwood City

39. Federal Emergency Management Agency (2000) Prestandard and commentary for the seismic rehabilitation of buildings FEMA 356. Federal Emergency Management Agency, Washington, D.C.

40. Federal Emergency Management Agency (1997) NEHRP guidelines for the seismic rehabilitation of buildings FEMA 273. Federal Emergency Management Agency, Washington, D.C.

41. American Society of Civil Engineers (2017) Seismic evaluation and retrofit of existing buildings: ASCE/SEl, 41-17. American Society of Civil Engineers, Reston

42. Meng X, Li T, Yang Q (2019) Experimental study on the seismic mechanism of a full-scale traditional Chinese timber structure. Eng Struct 180:484-493. https://doi.org/10.1016/j.engstruct.2018.11.055

43. Wang Z, Martinez-Vazquez P, Zhao B (2020) Pushover analysis of structures subjected to combined actions of earthquake and wind. Eng Struct. https://doi.org/10.1016/j.engstruct.2020.111034

44. Endo Y, Hanazato T (2018) Seismic analysis of a three-tiered pagoda temple affected by the 2015 Gorkha Earthquake. Int J Archit Herit 14:457-470. https://doi.org/10.1080/15583058.2018.1550534

45. Grillanda N, Valente M, Milani G, Chiozzi A, Tralli A (2020) Advanced numerical strategies for seismic assessment of historical masonry aggregates. Eng Struct. https://doi.org/10.1016/j.engstruct.2020.110441

46. Freeman S (1998) Development and use of capacity spectrum method. Proceedings of The IEEE - PIEEE. Seattle, Oakland, 1998

47. Fajfar P (1999) Capacity spectrum method based on inelastic demand spectra. Earthq Eng Struct Dyn 28(9):979-993. https://doi.org/10.1002/ (SICl)1096-9845(199909)28:9\%3c979::AID-EQE850\%3e3.0.CO;2-1

48. Chopra AK, Goel RK (2010) A modal pushover analysis procedure for estimating seismic demands for buildings. Earthq Eng Struct Dyn 31(3):561-582. https://doi.org/10.1002/eqe.144 
49. Kreslin M, Fajfar P (2012) The extended N2 method considering higher mode effects in both plan and elevation. Bullet Earthqu Eng 10(2):695715. https://doi.org/10.1007/s10518-011-9319-6

50. CSI (2017) SAP 2000 software, version 22. Computer and Structures, Inc

51. Gunaydin M, Demirkir C, Altunisik AC, Gezer ED, Genc AF, Okur FY (2021) Diagnosis and monitoring of historical timber Velipasa Han building prior to restoration. Int J Archit Herit. https://doi.org/10.1080/15583058.2021. 1919239

52. Ministry of Housing and Urban-Rural Development of the People's Republic of China (2017) Standard for design of timber structures GB5005-2017. China Architecture and Building Press, Beijing

53. Ministry of Housing and Urban-Rural Development of the People's Republic of China (2020) Technical code for maintenance and strengthening of ancient timber buildings GB/T50165-2020. China Architecture and Building Press, Beijing

54. Hua Y, Chun Q (2021) Effect of Pu-zuo on progressive collapse of Chinese ancient timber buildings of Jiangnan area in the Song \& Yuan dynasties. J Civil Environ Eng. https://doi.org/10.11835/j.issn.2096-6717.2021.115 (in Chinese)

55. Ministry of Housing and Urban-Rural Development of the People's Republic of China (2016) Code for seismic design of building GB 50011-2010. China Architecture and Building Press, Beijing

56. Ribeiro FLA, Neves LAC, Barbosa AR (2017) Implementation and calibration of finite-length plastic hinge elements for use in seismic structural collapse analysis. J Earthqu Eng 21(7-8):1197-1219. https://doi.org/10. 1080/13632469.2015.1036327

57. Chun Q, Zhang Y, Pan J (2013) Experiment on flexural behavior of timber beams strengthened with near-surface mounted CFRP rods. J PLA Univ Sci Tec (Nat Sci Ed) 14:190-194 (in Chinese)

58. Standardization Administration of China (2016) Seismic ground motion parameters zonation map of China GB 18306-2015. Chinese Standards Press, Beijing (in Chinese)

59. Chen Z, Zhu E, Pan J, Wu G (2016) Energy-dissipation performance of typical beam-column joints in Yingxian Wood Pagoda: experimental study. J Perform Constr Facil. https://doi.org/10.1061/(asce)cf.1943-5509. 0000771

\section{Publisher's Note}

Springer Nature remains neutral with regard to jurisdictional claims in published maps and institutional affiliations.

\section{Submit your manuscript to a SpringerOpen ${ }^{\circ}$ journal and benefit from:}

- Convenient online submission

- Rigorous peer review

- Open access: articles freely available online

- High visibility within the field

- Retaining the copyright to your article 